\title{
石墨烯导电墨水研究进展：制备方法、印刷技术及应用
}

姜欣 ${ }^{1,2}$, 赵轩亮 ${ }^{1,2}$, 李晶 ${ }^{1}$, 林舒媛 ${ }^{1,2}$, 朱宏伟 ${ }^{1,2 *}$

1. 清华大学材料科学与工程学院, 新型陶瓷与精细工艺国家重点实验室, 北京 100084;

2. 清华大学微纳米力学与多学科交叉研究中心, 北京 100084

* 联系人, E-mail: hongweizhu@tsinghua.edu.cn

2017-03-14 收稿, 2017-05-12 修回, 2017-05-15 接受, 2017-06-19 网络版发表

国家自然科学基金(51372133, 51672150)资助

摘要传统印刷技术与微电子制造的交叉技术一印刷电子技术的发展得益于微纳米材料制备技术的成熟. 二 维纳米碳材料石墨烯由于其独特的结构和突出的性能，可与传统金属或高聚物材料共同作为导电墨水主要导电组 分. 本文讨论了目前石墨烯导电墨水制备中的关键问题、不同制备方案及其优劣之处; 评述了石墨烯导电墨水印 刷工艺的研究进展, 包括传统印刷技术和新型印刷技术中的应用与难点. 最后, 总结了石墨烯导电墨水在柔性功 能器件(基本电路元件、能量存储和力学/化学传感器件等)中的应用现状.

关键词印刷电子, 石墨烯, 纳米碳材料, 导电墨水, 柔性电子

微电子制造业基础为微电子学, 即“研究在固体 (主要为半导体)材料上构成的微小化电路、子系统及 系统的电子学分支”. 微电子制造业发展成熟, 其代 表工艺为在脆性半导体 (如硅)上进行掺杂、光刻、薄 膜制备等. 国家标准《印刷技术术语》中定义“印刷” 为“通过印版或其他方式将原稿上的图文信息转移到 承印物上的工艺技术”. 印刷制造业的主要工艺为平 版、凹版、凸版、喷墨印刷等, 在包括纸、高聚物、 金属、陶瓷等基底上实现微米级的印刷. 印刷技术在 计算机及自动化工艺的辅助下, 可以实现高速率、高 质量的输出. 微电子制造与印刷制造业本是两种完 全不相关的制造业, 但随着微纳米材料制备技术与 工艺的发展, 印刷墨水从传统墨水扩展至纳米粒子、 导电高聚物、生物高分子分散液等新型功能性墨水. 印刷功能性墨水制备微电子器件的过程即是将传统 的信息转移印刷拓展至新型的功能性印刷, 从而实 现微电子制造业与印刷业的交叉.

微电子制造中的图案化过程包括薄膜制备、掺
杂、光刻等多个步骤，期间产生较多废弃副产物，且 对设计制造技能的需求很高. 由于精密掩膜板成本 较高, 需要大批量生产制造相同的产品以降低成本, 牺牲了产品的多样性. 传统微电子制造的主要特点 在于工艺稳定、精度高、产量大, 但小批量生产时成 本很高. 由于以脆性半导体硅作为基底, 在柔性集成 电路上制造存在困难. 相对地, 传统印刷工艺的特点 在于可以实现高质量、高速率的印刷, 适用于纸、聚 合物、玻璃、金属等任意基底. 虽然印刷精度有限，但 某些工艺中产品多样化并不会增加制造成本, 因此 可以实现按需打印、无需实物库存, 特别适合于个人 定制, 实现零技能制造、便携制造与净成形. 微电子 制造与印刷业的交叉学科一印刷电子制造结合了 两者的特点, 主要优势在柔性集成电路制造和多品 种小批量定制式生产. 印刷技术尤其利于平行集成 不同功能材料, 如微纳米金属粒子、导电聚合物、生 物高分子等不同材质均可用于印刷电子技术. 引人 新工艺时仅需更换墨水而无需更换印刷设备, 在低

引用格式: 姜欣, 赵轩亮, 李晶, 等. 石墨烯导电墨水研究进展: 制备方法、印刷技术及应用. 科学通报, 2017, 62: 3217-3235 Jiang X, Zhao X L, Li J, et al. Recent developments in graphene conductive ink: Preparation, printing technology and application (in Chinese) Chin Sci Bull, 2017, 62: 3217-3235, doi: 10.1360/N972017-00288 
成本下实现材料的无限组合, 设计空间无限. 需要强 调的是, 传统微电子制造与印刷电子作为不同的制 造工艺, 具有各自的优势与劣势. 印刷电子不可能替 代传统微电子制造, 印刷电子技术的发展将填补微 电子制造中部分空白领域, 二者之间是互相补充、互 相兼容的关系.

印刷电子技术中, 功能化印刷墨水对于电子器 件的性能至关重要. 印刷墨水是一种包含了微纳米 材料、稳定剂和流变改性剂的多组分系统. 印刷电子 器件的不同组成部分需要不同性能的墨水, 例如, 在 印刷薄膜晶体管时, 有源层使用半导体类型的墨水, 电极使用导电型墨水, 介电层使用绝缘型墨水 ${ }^{[1]}$. 导 电型墨水在具有传统墨水的稳定性、低成本和印刷适 性的同时, 应具有优良的载流子迁移率、功能稳定 性、可重复性, 同时避免过于复杂或极端的后续处理. 因此, 从传统印刷的单纯信息转移拓展至印刷电子 的功能化制造的进程, 与微纳米材料的研究发展密 切相关 ${ }^{[2]}$. 目前, 应用于印刷导电线路的微纳米材料 主要包括纳米碳材料 ${ }^{[3 \sim 5]}$ 、金属纳米材料 ${ }^{[6 \sim 8]}$ 、高聚 物 ${ }^{[9 \sim 12]}$ 等. 其中, 金属纳米粒子的导电机理为自由电 子移动, 主要使用金、银、铜、铝 4 类金属 ${ }^{[2,13,14]}$. 金 银纳米粒子或纳米线具有优秀的抗氧化与导电性能, 但成本高; 铜与铝纳米粒子或纳米线导电性能优良, 但易氧化. 由于金属的尺寸降低至纳米尺寸时, 导电 性能会大幅度改变, 因此金属纳米粒子在印刷后一 般需要后续处理(如烧结或还原处理)来提升导电性 能, 增加了工艺的复杂度, 限制了在高聚物基底上的 应用. 同时, 贵金属作为一种有限资源, 印刷电子材 料的回收再利用也是一项亟待解决的问题. 导电高 聚物材料主要包括聚苯胺、聚吡咯、聚噻吩及其衍生 物, 其导电性能有限, 在长期稳定性上也略有不 足 ${ }^{[2]}$. 纳米碳材料在电学、光学、热学、力学等方面 具有优异性能, 是近期研究的热点 ${ }^{[15]}$. 纳米碳材料主 要包括零维的富勒烯 $\left(\mathrm{C}_{60}\right)$ 、一维的碳纳米管 (carbon nanotubes, CNT)、二维的石墨烯(graphene). 这三种碳 的同素异形体化学键相似而维度不同, 结构的差异 使其具有截然不同的性能. 零维的富勒烯并不导电, 在 $18 \mathrm{~K}$ 左右时具有超导性能. 由于其独特的足球状 结构, 富勒烯在功能化后具有独特的光学和电学性 能. 一维的碳纳米管和二维的石墨烯, 结构十分相 似, 具有优良的热传导性能和高比表面积、力学强度 和化学稳定性. 碳纳米管主要通过管壁进行载流子
传输, 因此管壁之间的合理搭接是提升碳纳米管墨 水导电性能的关键. 碳纳米管在印刷半导体器件时 具有一定的难度，所制备的墨水一般同时包含金属 型和半导体型的碳纳米管. 石墨烯是一种可以很好 地满足导电墨水性能要求的具有潜力的材料. 自 2004年被发现以来 ${ }^{[16]}$, 石墨烯逐渐成为研究热点, 归因于其优异的基本物理化学性能 ${ }^{[17]}$. 单层石墨烯 具有 $97.7 \%$ 的可见光透过率, 载流子迁移率高达 $2.5 \times$ $10^{5} \mathrm{~cm}^{2} /(\mathrm{V} \mathrm{s})$, 力学性能优异, 特别适用于印刷电子 器件. 石墨烯可通过沼气等可再生碳源制备, 是一种 可再生循环材料, 对可持续发展具有重要意义 ${ }^{[3]}$. 基 于以上因素, 石墨烯导电墨水在印刷电子领域中具 有巨大的应用潜力 ${ }^{[13,18]}$.

本文系统总结了当前石墨烯墨水制备技术、印刷 工艺和应用的研究进展(图1). 首先概述了石墨烯导 电墨水的制备方法，总结了石墨烯墨水制备工艺的 关键问题、不同分散技术的差异和研究进展, 以及石 墨烯墨水的常用性能参数. 随后, 按传统印刷业的分 类方法简要概述了基础印刷技术的分类及特点，同 时介绍了在传统印刷之外的新型图案化技术. 最后, 总结了石墨烯导电墨水在不同领域中的应用及其优 势所在, 预测了未来的发展趋势.

\section{1 石墨烯导电墨水的制备方法}

2004年, Novoselov等人 ${ }^{[16]}$ 通过实验证实石墨烯

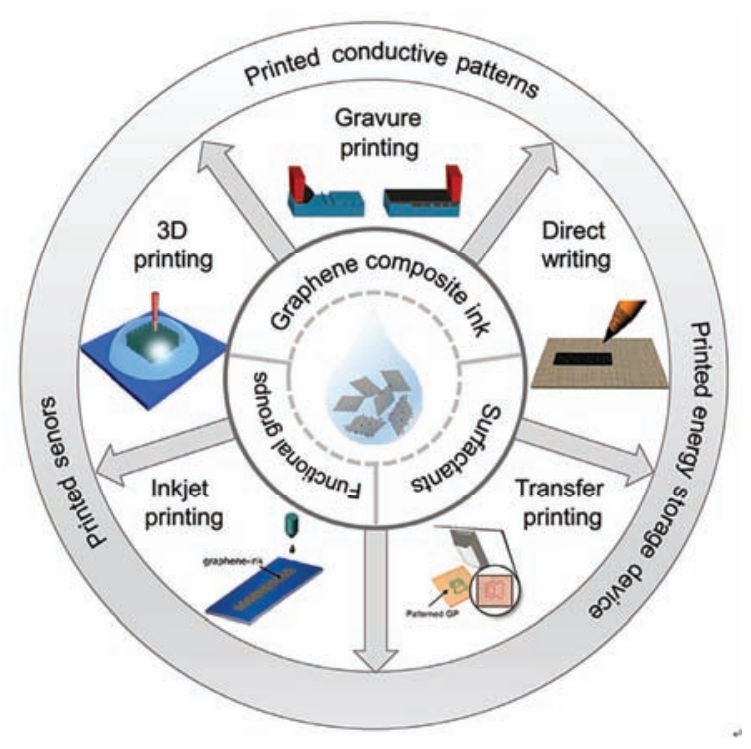

图 1 (网络版彩色)石墨烯导电墨水的印刷工艺与应用示意图 ${ }^{[19-23]}$

Figure 1 (Color online) Printing methods and applications of graphene conductive ink ${ }^{[19-23]}$ 
可以稳定存在, 二人也因发现石墨烯获得 2010 年的 诺贝尔物理学奖. 石墨烯本征上是一种由碳原子以 $\mathrm{sp}^{2}$ 杂化方式构成的单原子厚度的二维材料, 具有独 特的结构和优异的光、电、力学等性能, 如单层石墨 烯仅吸收 $2.3 \%$ 的可见光 ${ }^{[24]}$, 载流子密度达到 $2.5 \times 10^{5}$ $\mathrm{cm}^{2} /(\mathrm{V} \mathrm{s})^{[25]}$, 热传导率为 $3000 \mathrm{~W} /(\mathrm{m} \mathrm{K})^{[26]}$, 弹性模量 达到 $1 \mathrm{TPa}$, 本征强度达到 $130 \mathrm{GPa}^{[27]}$, 比表面积的理 论值为 $2630 \mathrm{~m}^{2} / \mathrm{g}^{[28]}$. 作为一种碳材料, 石墨烯可由 能循环再生的甲烷作为碳源制取 ${ }^{[29]}$, 是一种可持续 发展的材料. 随着制备技术的不断发展, 石墨烯的成 本也将进一步降低. 石墨烯是一种集成了上述优良 电学、力学、热学性能的材料, 将在印刷电子器件领 域, 特别是柔性透明电子器件制造方面具有广阔前景.

本节概述了石墨烯导电墨水的制备研究进展, 包括石墨烯制备方法、官能团修饰石墨烯墨水、表面 活性剂辅助分散石墨烯墨水、石墨烯复合墨水等. 在 传统印刷行业中, 印刷油墨在常规印刷工艺中的应 用研究已经较为完善, 具有良好的印刷适性. 目前, 石墨烯导电墨水主要存在以下问题: 浓度低、易团 聚、打印适性不良 ${ }^{[2]}$, 主要是因为石墨烯作为一种单 原子厚度的二维材料, 具有非常高的比表面积, 层片 间存在的范德华力使层片在较低浓度时也容易发生 团聚和沉淀. 因此, 制备高浓度且不易团聚的石墨烯 导电墨水是本领域中最核心的问题. 实际印刷工艺 中, 石墨烯导电墨水的印刷适性调控对印刷图案质 量具有重要影响. 印刷适性主要表现于墨水的物化 性质, 如黏度值、表面张力、密度、沸点等.

\section{1 石墨烯制备方法}

石墨烯的制备方式可以分为“自上而下”与“自下 而上”2种方法 ${ }^{[30,31]}$. “自上而下”方法即将石墨或碳纳 米管等原材料通过一定手段剥离为单层或少数层的 石墨烯, 如机械剥离法、氧化还原法、溶剂剥离法等; 而“自下而上”方法即通过一定手段将碳源裂解为碳 原子后, 在限定的基底上原位生长单层或少数层的 石墨烯, 如化学气相沉积、外延生长、取向附生法等. 大体而言, “自上而下”方法中通过液相法制备的石墨 烯层片, 可直接应用于印刷工艺, 包括凹版印刷、喷 墨印刷等. 通过 “自下而上”方法制备的石墨烯薄膜 可通过转移印刷方法组装为器件. 本节的概述重点 为可应用于石墨烯导电墨水的石墨烯制备, 因此着 重于“自上而下”方法.
目前应用于石墨烯导电墨水的石墨烯制备方法 主要包括还原氧化法、溶剂剥离法及电化学剥离法 等. 氧化还原法通过将天然石墨粉或经过预处理的 石墨粉经过氧化后利用化学能剥离出单层或少数层 的氧化石墨烯(graphene oxide, GO), 然后采用不同方 法将 GO还原为还原氧化石墨烯 (reduced graphene oxide, $\mathrm{rGO}$ ), 如化学还原 ${ }^{[32]}$ 、电化学还原 ${ }^{[33]}$ 、光催化 还原 ${ }^{[34]}$ 、热还原 ${ }^{[35]}$ 、超声还原 ${ }^{[36]}$ 等。通过改良 Hummers法 ${ }^{[37]}$ 制备 $\mathrm{GO}$ 是目前较为常用且可实现大批 量工业化生产的方法. GO表面具有大量的亲水官能 团, 表现出较好的亲水性, 因此可以获得分散良好的 高浓度水分散液. 同时, GO表面的官能团可用于接 枝以制备特异性功能的材料. 通过氧化还原法制备 的石墨烯层片可在液体中保持分散状态，无需经过 干燥后再分散的过程, 可以避免干燥过程中的团聚. 但GO在还原过程中需去除官能团, 引起 $\mathrm{rGO}$ 的层片 缺陷, 导致层片电导率有所下降. 氧化还原法制备石 墨烯的研究热点主要为还原过程低毒化、提升 $\mathrm{rGO}$ 层 片质量等. Fernandez-Merino等人 ${ }^{[38]}$ 提出与高毒性的 水合肼、嗍氢化钠等还原剂相比, 抗坏血酸可以高效 地在多种溶剂中对 GO进行还原, 且制备的石墨烯具 有更高的电导率. Kumar等人 ${ }^{[39]}$ 提出无化学处理的温 和热退火处理用于还原 $\mathrm{GO}$, 可以在保留部分含氧官 能团的同时将导电率提升 4 个数量级.

溶剂剥离法是将高质量的原始石墨粉末或经过 一定预处理的石墨粉末分散于无机或有机溶剂中, 利用机械能将石墨片剥离为单层或少数层的石墨烯 层片. 其中, 机械能的输出方法包括超声波破碎、机 械摚拌等物理手段. 超声剥离法制备的石墨烯不需 氧化还原的化学剥离过程, 而是通过物理作用将石 墨层层剥离, 得到均匀分散在有机溶剂中的石墨烯 悬浊液. 采用超声剥离法制备的石墨烯晶化程度高、 缺陷少, 因此电学性能比较好. 不同溶剂环境下制备 石墨烯所需的剥离能不同, 溶剂表面张力与单位面 积石墨层片的表面能匹配程度越高, 则所需剥离能 越低, 分散效果越好 ${ }^{[40]}$. 具有良好剥离效果的溶剂 一般具有毒性. 目前, 研究热点主要围绕着提升石墨 烯品质与产率，溶剂无毒化等方面。2008年, Hernandez等人 ${ }^{[40]}$ 提出通过探针超声剥离法在有毒有 机溶剂 $N$-甲基-吡咯烷酮 $(N$-methyl-pyrrolidone, NMP) 中制备了单层石墨烯，获得了 $1 \%$ 的单层石墨烯产率. Torrisi等人 ${ }^{[19]}$ 在NMP溶剂中对石墨粉进行了 $9 \mathrm{~h}$ 的超 
声处理, 制备了石墨烯分散液用于印刷. $\mathrm{Li}$ 等人 ${ }^{[41]}$ 提 出了溶剂交换法, 即在有毒有机溶剂二甲基甲酰胺 (dimethylformamide, DMF) 中进行石墨烯剥离, 再以 乙醇/松油醇复合溶剂替换DMF, 制备了低毒的石墨 烯墨水. Secor等人 ${ }^{[5,18,20,42,43]}$ 研究了乙醇/乙基纤维素 溶液环境下超声辅助剥离制备石墨烯分散液的工艺, 采用溶剂替换法制备了低毒石墨烯导电墨水(图2(a)). 乙基纤维素在石墨烯层片表面形成均匀的包覆, 有 效提升了超声剥离效率, 石墨烯层片厚度约为 $2 \mathrm{~nm}$, 尺寸约 $50 \mathrm{~nm} \times 50 \mathrm{~nm}$. 通过离心法去除未被剥离的石 墨粉后, 引人盐溶液将乙基纤维素与石墨烯絮凝; 所 获得的石墨烯-乙基纤维素粉末可分散在多种不同有 机溶剂, 形成高浓度的稳定分散液. 该方法可用于制 备多种不同性能的石墨烯墨水, 应用于不同的印刷 方法, 但缺点是工序复杂、产率较低.

电化学剥离石墨烯是在电解质溶液中将石墨作 为阳极 (或阴极)进行电化学剥离, 制备单层或少数层 石墨烯. 石墨作为阴极时, 在电流作用下插层粒子聚 集使石墨膨胀剥离形成石墨烯(图2(b) $)^{[44]}$. 石墨作为 阳极时, 电解质阴离子在电流作用下被氧化, 形成的 中间过渡产物氧化了阳极石墨表面, 产生的微小气 泡和阴离子插层相互作用使石墨膨胀剥落得到石墨 烯 ${ }^{[45,46]}$. 电化学剥离是近期石墨烯制备的研究热点
之一, 其优点在于单层及少数层石墨烯产率较高, 石 墨烯片层碳氧比高、表面缺陷较少、导电率高 ${ }^{[47,48]}$. 电化学剥离石墨烯制备过程中可引人化学处理, 同 步完成石墨烯的官能化, 如利用重氮盐进行同步氮 掺杂 ${ }^{[49]}$. 整个过程在溶液环境下进行, 有利于石墨 烯导电墨水的制备.

“自下而上”方法同样可以直接获得石墨烯层片 的分散液, 如水热法. 在密闭反应釜中将金属钠加人 乙醇, 辅助以超声, 可以生成稳定分散的石墨烯层

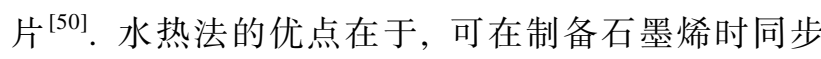
进行掺杂(如同步氮掺杂 ${ }^{[51]}$ ), 对于提升石墨烯层片的 电导性能, 及功能化修饰石墨烯以制备独特用途的 功能墨水具有一定的优势.

\section{2 官能团修饰石墨烯墨水}

采用纯净的石墨烯分散液作为导电墨水进行印 刷, 可避免表面活性剂等添加剂对石墨烯墨膜电学 性能的影响, 但纯净石墨烯在常见溶剂中的分散性 能较差, 极大限制了石墨烯在印刷墨水中的实际应 用. Hernandez等人 ${ }^{[40]}$ 经理论计算得出, 单一溶剂石 墨烯分散液浓度的理论最高值为 $0.01 \mathrm{mg} / \mathrm{mL}$, 不宜 直接用于印刷. Han等人 ${ }^{[52]}$ 提出用溶剂交换法将 NMP 溶剂剥离的石墨烯转移至水/乙醇混合溶剂中, 制备 (a)
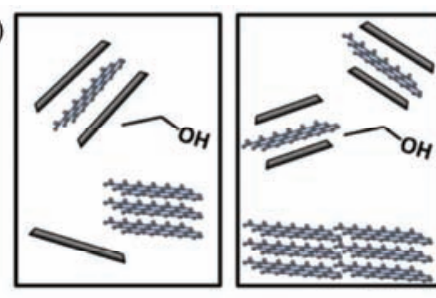
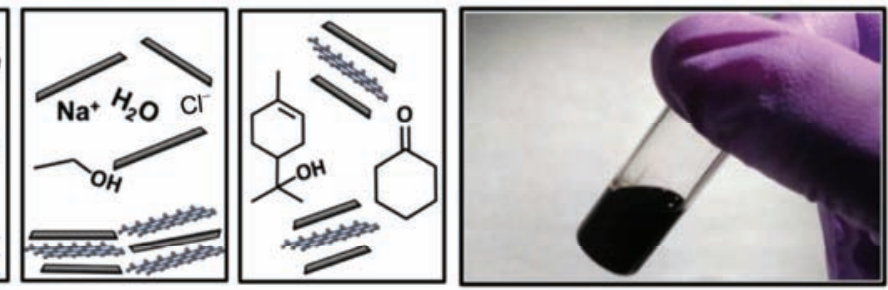

(b)

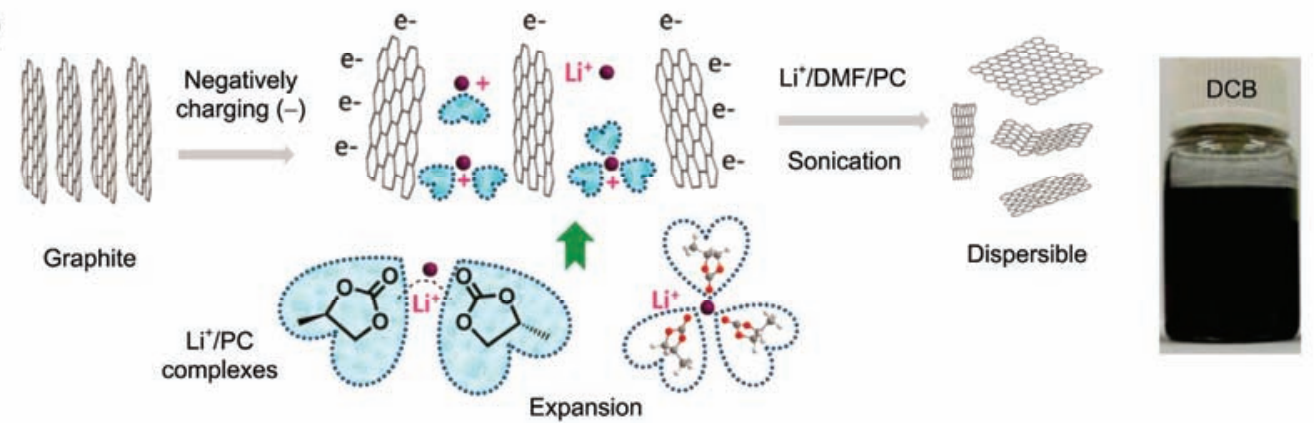

图 2 (网络版彩色)石墨烯导电墨水制备方法示意图. (a) 采用乙基纤维素辅助剥离石墨烯制备石墨烯导电墨水 ${ }^{[42]}$; (b) 以电化学剥离方法制备 石墨烯导电墨水 ${ }^{[44]}$

Figure 2 (Color online) Schematic illustration of the graphene preparation methods. (a) Ethyl cellulose assisted liquid-phase exfoliation ${ }^{[42]}$. (b) Electrochemical stripping ${ }^{[4]}$ 
了浓度为 $0.43 \mathrm{mg} / \mathrm{mL}$ 的石墨烯导电墨水. 但纯净石 墨烯分散液的导电墨水浓度依然不高, 在印刷电子 时需要重复多次印刷才能获得可实用的电学性能, 极大限制了其实际应用价值.

为了增强石墨烯分散液的稳定性，可对石墨烯
进行共价修饰，即引人官能团. GO是一种富含亲水 官能团的石墨烯衍生物(图3(a)), 基于GO的功能性墨 水在印刷电子器件中具有应用前景. 由于官能团的 存在, GO可均匀稳定地分散在水及其他有机溶剂中, 形成高浓度、分散状况良好且可长期保持稳定的分散

(a)
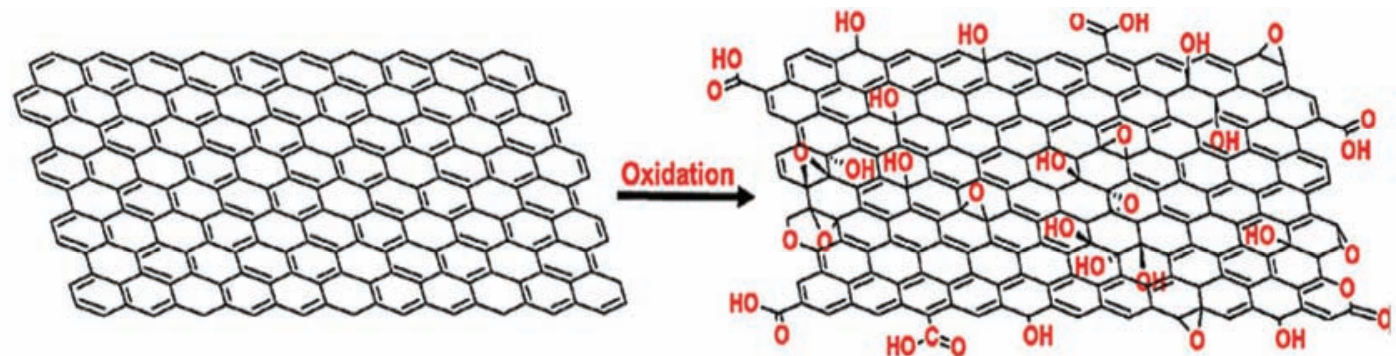

(b)

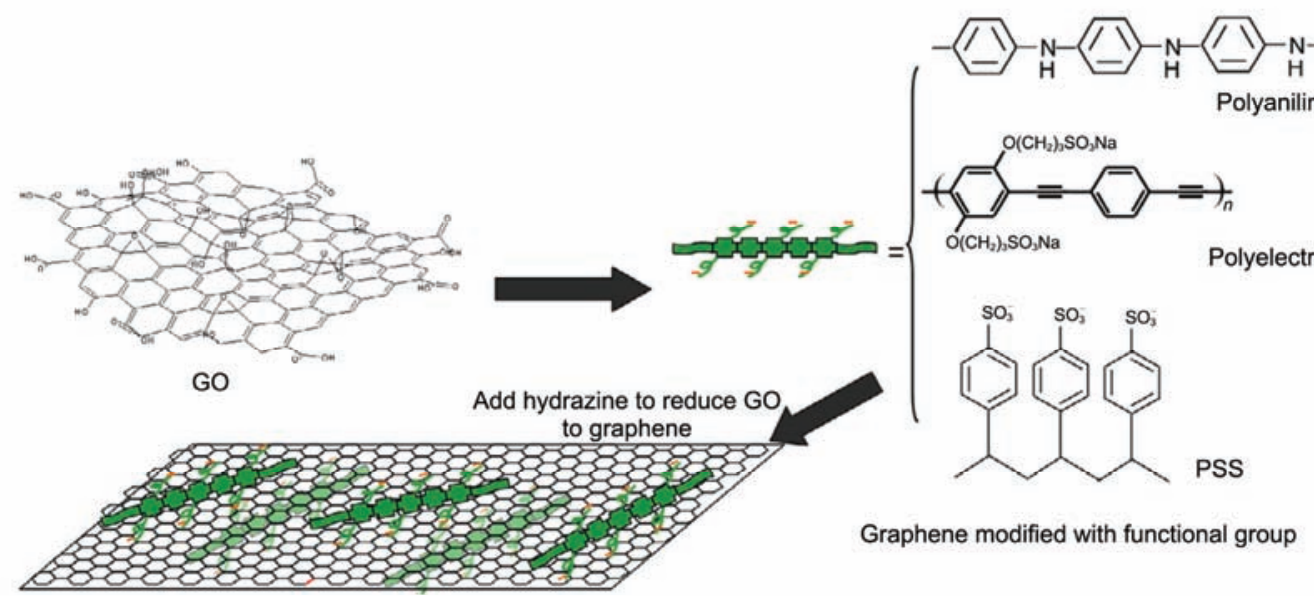

(c)

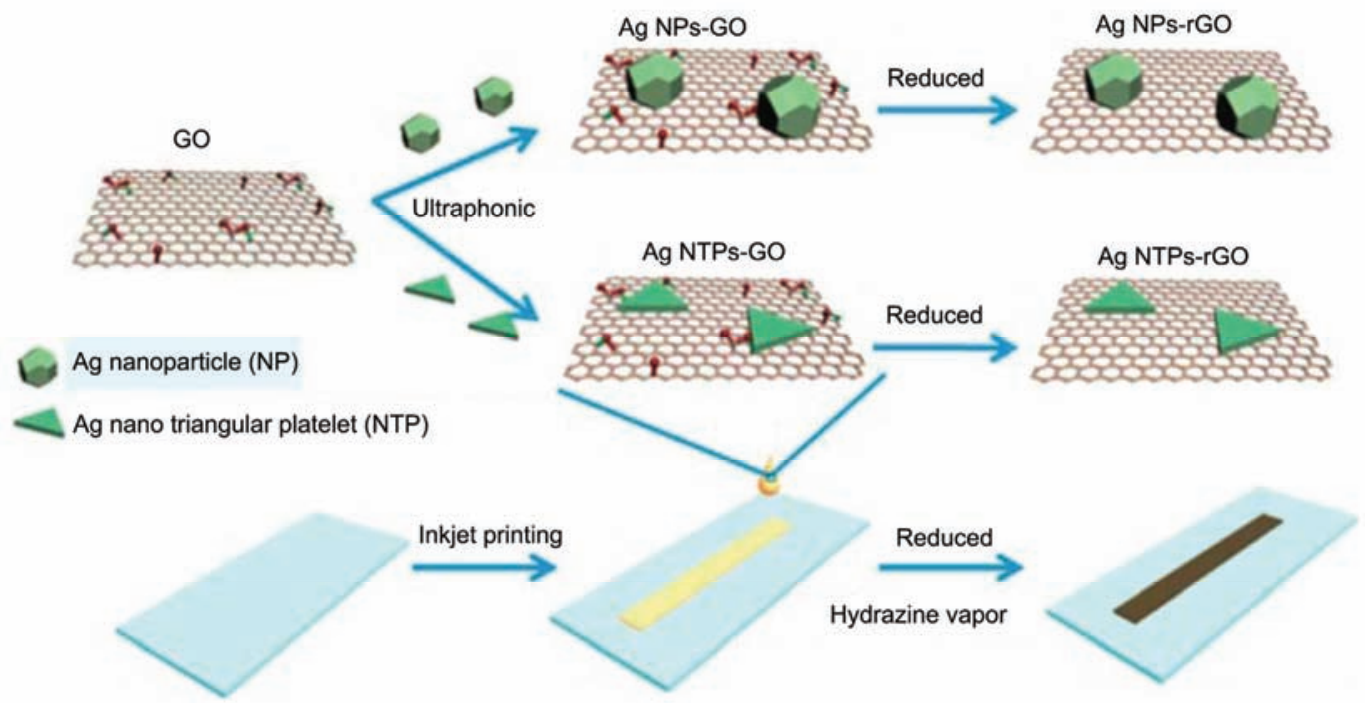

图 3 (网络版彩色)石墨烯导电墨水不同的化学结构示意图. (a) $\mathrm{GO}^{[53]}$; (b) 用聚吡咯、聚电解质和PSS修饰的石墨烯导电墨水 ${ }^{[54]}$; (c) 石墨烯与 银纳米颗粒复合的导电墨水 ${ }^{[55]}$

Figure 3 (Color online) Different chemical structures of the graphene inks. (a) $\mathrm{GO}^{[53]}$; (b) graphene functionalized by polyaniline, polyelectrolyte, PSS anions ${ }^{[54]}$; (c) Ag nanotriangle platelet-rGO (Ag NTP-rGO) and Ag polyhedral nanoparticle-rGO composite conductive ink ${ }^{[55]}$ 
液 ${ }^{[56,57]}$. 高浓度 $\mathrm{GO}$ 分散液可作为墨水直接用于印刷, 所获得的 $\mathrm{GO}$ 图案再进行还原处理, 如在氮气氛中热 还原 ${ }^{[58]}$ 、碘化氢/溴化氢化学还原 ${ }^{[59,60]}$. 2011年, Le等 人 ${ }^{[61]}$ 以 $2 \mathrm{mg} / \mathrm{mL}$ GO作为前驱体, 喷墨印刷在具有高 热稳定性的聚酰亚胺(polyimide, PI)高聚物上, 氮气 环境下 $200^{\circ} \mathrm{C}$ 经过 $12 \mathrm{~h}$ 热还原形成导电通路. Huang等 人 $^{[62]}$ 提升了 $\mathrm{GO}$ 浓度, 达到 $9 \mathrm{mg} / \mathrm{mL}$, 并用于打印电 路和化学传感器中的导电图案. Shin等人 ${ }^{[63]}$ 将 GO喷 墨印刷在聚对苯二甲酸乙二醇酯 (polyethylene terephthalate, PET)基底上, 在真空条件 $90^{\circ} \mathrm{C}$ 利用水合肼 和氨的蒸汽进行化学还原, 印刷分辨率达到了 70 $\mu \mathrm{m}$. Mei和Zhang ${ }^{[64]}$ 利用 $0.9 \mathrm{mg} / \mathrm{mL}$ 的GO水分散液印 刷了一种多用途可视化的生物效应标记. 印刷 GO墨 水后, 不同还原方法的工艺参数控制对石墨烯电路 的电导率具有较大影响, 如Wlasny等人 ${ }^{[60]}$ 研究了用 溴化氢还原 GO图案时, 还原时间与温度对印刷图案 电导率的影响, 并提出最佳还原工艺参数为 $50 \%$ 溴 化氢溶液在 $90^{\circ} \mathrm{C}$ 下还原 $120 \mathrm{~min}$.

$\mathrm{GO}$ 墨水的优点为浓度高、稳定性好、毒性低. 印 刷高浓度 $\mathrm{GO}$ 墨水可减少为获得优良导电性能电路所 需要的印刷次数; 但 $\mathrm{GO}$ 表面大量缺陷的存在使其几 乎完全不导电, 因此需要热还原或化学还原等后处 理. 热还原主要包括低温 $\left(100^{\circ} \mathrm{C}\right.$ 以下)长时间保温还 原 ${ }^{[39]}$ 和高温 $\left(300{ }^{\circ} \mathrm{C}\right.$ 以上) 还原 ${ }^{[65]}$. 化学还原使用的还 原剂一般为水合肼或碘化氢. $\mathrm{rGO}$ 结构上存在一定的 缺陷, 增强了载流子的散射, 因此 $\mathrm{GO}$ 墨水制备的导 电图案的电学性能有一定程度的降低.

\section{3 表面活性剂辅助分散石墨烯墨水}

采用表面活性剂辅助分散是提升石墨烯导电墨 水中石墨烯分散稳定性的常见方法. 处于溶液环境 的石墨烯由于 $\pi$ 电子的存在, 层片表面带有一定的负 电荷, 因此采用表面活性剂吸附在石墨烯层片间, 可 以有效地降低其团聚概率. 表面活性剂通过范德华 力、氢键、静电作用、 $\pi-\pi$ 相互作用等对石墨烯层片 进行非共价修饰, 提升石墨烯分散液的稳定性 ${ }^{[53]}$. 另外, 表面活性剂可有效地改变溶剂的表面能, 使溶 剂与石墨烯表面能更加匹配、分散更加稳定, 可以替 换有毒溶剂(如DMF或NMP). 2010年, Dua等人 ${ }^{[66]}$ 首 次提出了将 $\mathrm{rGO}$ 水分散液作为导电墨水进行打印的 概念. 采用抗坏血酸还原 GO, 利用Triton-X100作为 分散剂, 制备稳定分散的石墨烯导电墨水 (3 mg/mL)
进行喷墨印刷, 构建了有机蒸汽传感器. Wei等人 ${ }^{[54]}$ 研究了不同类型的表面活性剂对石墨烯表面的修饰 作用, 包括室温离子液体、聚苯胺、多种聚电解质和 聚苯乙烯磺酸盐 (poly(sodium- $p$-styrenesulfonate), PSS) 等, 并在PSS的辅助分散下获得最高 $0.5 \mathrm{mg} / \mathrm{mL}$ 的石墨烯水分散液(图3(b)). Arapov等人 ${ }^{[67]}$ 研究了 $N$ 乙烯基-2-吡咯烷酮-醋酸乙烯共聚物作为导电墨水表 面活性剂的可行性，采用的溶剂是正丁醇与异丙醇; 同时验证了此类有机表面活性剂对于不同纳米结构 碳材料的适用性. Lim等人 ${ }^{[68]}$ 采用毒性低的聚乙烯醇 (polyvinyl alcohol, PVA)作为分散剂, 辅助剥离分散 $\mathrm{rGO}$, 并制备了稳定均一的rGO/PVA胶体溶液用于喷 墨印刷, 该胶体溶液可长期稳定保存.

在石墨烯导电墨水制备研究中, 纤维素醚类高 聚物(羧甲基纤维素、乙基纤维素等)是一类重要的辅 助分散剂. 离子型纤维素醚与石墨烯层片间具有良 好的相互作用力, 有助于石墨烯层片的稳定分散或 在有机溶剂环境下辅助剥离石墨烯. 印刷完毕后, 纤 维素醚可通过温和加热处理分解. $\mathrm{Lu}$ 等人 ${ }^{[69]}$ 首次提 出将纤维素醚乙基纤维素应用于石墨烯的分散, 制 备了 $\mathrm{rGO}$ 的稳定分散液. Secor等人 ${ }^{[42]}$ 提出乙基纤维 素辅助分散石墨烯墨水的制备工艺, 在酒精与乙基 纤维素混合溶液中对石墨进行超声剥离, 制备了高 浓度石墨烯导电墨水并应用于喷墨印刷, 乙基纤维 素分解 $\left(250^{\circ} \mathrm{C}\right.$ 退火处理 $\left.30 \mathrm{~min}\right)$ 后, 墨膜电导率达到 $(2.5 \pm 0.2) \times 10^{4} \mathrm{~S} / \mathrm{m}$. Secor等人 ${ }^{[20]}$ 进一步优化了石墨烯 导电墨水的制备参数, 得到了应用于凹版印刷的高 浓度、高黏度石墨烯导电墨水, 石墨烯浓度达到 20 $\mathrm{mg} / \mathrm{mL}$, 通过调整松油醇的比例可以调节黏度. $250^{\circ} \mathrm{C}$ 退火处理 $30 \mathrm{~min}$ 后, 墨膜电导率提升至 $1 \times 10^{5}$ $\mathrm{S} / \mathrm{m}$, 且形成的导电图案经过 500 次弯折循环后电导 率几乎没有下降. 为了避免热处理对基底的限制, Secor等人 ${ }^{[5]}$ 采用脉冲光对印刷图案快速退火分解乙 基纤维素, 退火后墨膜导电率约 $2.5 \times 10^{4} \mathrm{~S} / \mathrm{m}$. 该制备 工艺具有溶剂低毒、黏度可调节且石墨烯含量高等优 点, 但是制备相对耗时且产量相对较低. 羧甲基纤维 素是一种阴离子型纤维素醚, 在石墨烯分散中也有 优良表现. Baker等人 ${ }^{[70]}$ 首次采用羫甲基纤维素作为 石墨烯导电墨水的表面活性剂. Sinar等人 ${ }^{[71]}$ 采用羧 甲基纤维素将石墨烯稳定分散于水和2-丁氧基乙醇 溶液中, 制备了水性石墨烯导电墨水. 喷墨印刷的图 案经热退火后, 其方阻低至 $100 \Omega / \mathrm{sq}$. 纤维素醚均匀 
包覆石墨烯层片后使其稳定分散, 适用于水与有机 溶剂, 低毒无害且可低温分解处理. 其不足之处在 于, 为了使石墨烯墨水的印刷电路获得最佳电学性能, 纤维素醚需要后处理, 增加了制备工艺的复杂度.

综上所述, 表面活性剂在石墨烯导电墨水制备 过程中不仅能够辅助分散石墨烯, 而且在液相剥离 石墨烯制备过程中可以提升剥离产率和质量. 但表 面活性剂对印刷墨膜的导电性能有一定的负面影响, 一般需要退火处理去除表面活性剂, 而退火过程增 加了工艺的复杂性, 也限制了基底的使用范围. 因 此, 开发新型表面活性剂以提升石墨烯导电墨水稳 定性, 同时避免对印刷图案导电性的影响是一个重 要的研究方向.

\section{4 复合材料导电墨水}

近期, 石墨烯与不同材料复合制备导电墨水是 研究热点之一, 如金属材料、高聚物分子等. 金属银 具有非常好的导电性能, 基于银纳米颗粒或银纳米 线的导电墨水在印刷电子中具有广泛应用, 但银的 价格昂贵且储量有限; 将石墨烯或 $\mathrm{GO}$ 与银纳米材料 复合, 可制备成本低廉且导电性能优良的复合导电

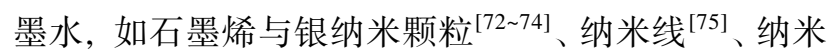
枝晶 ${ }^{[76]}$ 复合. $\mathrm{Li}$ 等人 ${ }^{[55]}$ 将银纳米颗粒与 $\mathrm{GO}$ 复合制备 了水性导电墨水(图3(c)), 通过喷墨印刷与化学还原 制备了透明导电线路, 其电阻率高达 $170 \Omega / \mathrm{cm}$, 可见 光透过率为 $90.2 \%$. 近期, Zhang等人 ${ }^{[73]}$ 用 $\mathrm{rGO}$, 银纳 米颗粒和PVP K30(辅助分散剂)复合制备了导电墨 水, 通过喷墨印刷的电导率高达 $2.0 \times 10^{3} \mathrm{~S} / \mathrm{m}$. Jabari 和 Toyserkani ${ }^{[74]}$ 将纳米银颗粒与石墨烯层片复合导 电墨水用于喷印, 制备的高柔性高导电图案的平均 电阻率为 $1.07 \times 10^{-4} \Omega / \mathrm{cm}$, 电阻率比同等条件下制备 的银纳米颗粒图案低了 2 个数量级. 在石墨烯与金属 纳米材料的复合墨水中, 金属纳米材料不仅可以降 低石墨烯层片间的接触电阻, 同时作为填充剂防止 石墨烯层片团聚沉淀.

导电高聚物, 如聚3,4-乙撑二氧噻吩: 聚苯乙烯 磺酸盐(PEDOT: PSS)或聚苯胺 (polyaniline, PANI), 在柔性电子器件领域具有广泛应用, 而与石墨烯和 高聚物的复合导电墨水可实现更加优良的分散稳定 性、导电性能和传感性能. Liu等人 ${ }^{[77]}$ 将石墨烯层片、 PEDOT:PSS和分散剂PH1000分散于DMF中形成稳定 均匀的复合导电墨水, 可稳定存储 1 个月以上; 其导
电图案的方阻低至 $500 \Omega / \mathrm{sq}$, 且具有良好的力学稳定 性, 循环弯折 1000 次以上时几乎保持不变. 高聚物聚 苯胺是一种广泛应用于柔性能量存储器件的导电高 聚物, 但是其缺点在于循环稳定性差且电阻值偏高. 石墨烯与聚苯胺复合导电墨水可用于印刷稳定的导 电网络, 在制备超级电容器方面具有一定潜力. $\mathrm{Xu}$ 等 人 $^{[78]}$ 制备了石墨烯与聚苯胺的水性复合导电墨水, 分散剂为十二烷基苯磺酸钠(SDBS), 并通过喷墨印 刷方法制备了具有良好电化学性能和长久循环寿命 的柔性超级电容器. Yuan等人 ${ }^{[79]}$ 通过聚苯乙烯磺酸 钠(sulfonate polystyrene, SPS)硬模板法制备了SPS: PEDOT纳米颗粒，进一步制备了SPS : PEDOT/GO复 合导电油墨; 通过喷墨印刷方法在PET基底上制备 的多层复合薄膜在热退火后实现了优良的湿度感测 特性.

\section{5 石墨烯导电墨水性能参数}

印刷制造业中, 影响印刷效果的墨水主要性能 参数为墨水的黏度 (Reynolds数, Re)、表面张力 (Weber 数, $\mathrm{We})$ 和密度 $(\mathrm{Ohnesorge} \text { 数, } \mathrm{Oh})^{[80,81]}$. 其中, $\mathrm{Oh}$ 数值 越低, 代表墨水黏度越高、表面张力越低; Oh数值越 高, 代表墨水黏度越低、表面张力越高, 易形成飞沫. 不同的印刷工艺具有不同的最适合的性能参数范围, 超出此范围的导电墨水用于印刷时, 可能会产生一 些不必要的溢出污渍, 导致印刷质量降低. 因此, 需 要通过添加表面活性剂、流变剂、稳定剂等添加剂来 修饰石墨烯导电墨水的性能参数.

除此之外，导电墨水与基底之间的浸润性对印 刷质量有很大的影响, 其主要参数为墨水的表面自 由能以及与基底之间的接触角. 这些参数可以通过 调整墨水的黏度、表面张力和密度进行控制. 同时, 基底的表面粗䊁度或温度、气氛等环境因素也会对导 电墨水的印刷质量产生影响, 对基底进行一定的预 处理对于提升印刷分辨率具有积极影响, 如基底表 面处理 ${ }^{[19]}$ 、温度气氛控制 ${ }^{[41]}$ 等.

\section{2 石墨烯导电墨水的印刷技术}

石墨烯导电墨水的印刷工艺继承自传统印刷制 造业, 主要使用的工艺包括喷墨印刷、凹版印刷、凸 版印刷等. 在功能化制造的研究中, 印刷方式并不限 于常规印刷方法，也包括如快速成形的笔画法、3D 打印等其他成膜技术. 下文将结合目前已报道的石 
墨烯墨水印刷技术应用, 简述不同类型印刷工艺的 特点. 不同的印刷技术可以实现不同的印刷效果.

\section{1 喷墨印刷}

喷墨印刷是将墨水液滴喷涂在期望喷墨的位置, 特点是无需预图案化, 可实现净成形的大批量快速 印刷技术, 在工业印刷或家用印刷具有广泛应用. 喷 墨印刷具有许多独特的优点, 如印刷成本较低、易于 使用、净成形、节省墨水且小批量定制式生产的成本 不会大幅上升. 在器件原型设计方面, 喷墨印刷机可 以集成多种类型的功能材料墨盒, 达到平行集成多 种功能材料的优点, 十分适用于实验室的快速原型 制造. 通过喷墨印刷方法可以制备多种能量转换微 器件(如超级电容器、太阳能电池、柔性电极等), 各 种类型的传感器 (如化敏传感器 ${ }^{[66]}$ 和热学传感器 ${ }^{[58]}$ ), 其他类型的电子器件 (如导电电路 ${ }^{[82]}$ 、声学致动器 ${ }^{[83]}$ 、 偶极子天线 ${ }^{[63]}$ 、薄膜晶体管 ${ }^{[68]}$ 等). 目前, 喷墨印刷 是石墨烯导电墨水研究领域最为常用的一种印刷方 法. 本小节将主要介绍喷墨印刷的印刷过程与特征, 概述目前对提升喷墨印刷效果的研究进展.

喷墨印刷的机制主要分为连续喷墨 (continuous inkjet, CIJ)和按需喷墨(drop on demand, DOD)两种方 式. 连续喷墨是一直喷出带有不同电荷的墨滴, 通过 电场作用控制墨滴的飞行轨迹. 其特点是喷印速度较 快, 未喷印的墨水可回收, 在不平整基底上的印刷效 果较好. 但石墨烯导电墨水在回收过程中易形成一定 程度的絮凝. 按需喷墨是在需要喷出墨滴的特定地点 才喷出墨滴, 其比较节省墨水使用量, 同时喷印的精 度较高. 因此, 按需喷墨更适用于印刷石墨烯导电墨 水, 既可以节省石墨烯用量, 也可以避免絮凝的发生.

喷墨印刷有 2 种不同的喷墨方式, 热感应式喷墨 (也称气泡式)和压电式喷墨. 热感应式喷墨是通过薄 膜电阻器在电压作用下发热, 将墨水喷出腔中的墨 水瞬间加热至过热, 墨水形成气泡并迅速膨胀破裂, 迫使微小墨滴沿着喷头飞出, 转移到承印基底上形 成图案. 当电压消失, 墨腔冷却, 气泡消失, 表面张 力吸引墨水重新充满墨腔, 整个过程需要数个微秒. 热感应式喷墨的喷头价格较低廉、易于更换、维护费 用较低; 但缺点是由于对墨水进行加热, 因此墨水中 的功能材料容易发生化学变化, 导致性能不稳定. 对 墨水的黏度、表面张力、密度等皆有一定的要求, 如 墨水黏度应控制在 $10 \mathrm{cP}$ 左右 ${ }^{[41]}$. 由于气泡破裂产生
的微小墨滴的体积和方向性不能完全控制, 从而影 响了印刷精度. 另外一种喷墨方式为压电式喷墨, 其 原理是压电晶体在电压作用下产生形变, 通过施加 电压使压电晶体产生伸缩, 将墨水从墨腔中挤出, 在 承印基底上形成图案. 压电式喷头的价格较高、不易 更换、维护费用较高. 但其优点在于对墨水的要求较 低, 可以实现多种不同类型的功能性墨水的印刷. 控 制电压可有效控制墨滴大小, 在常温下即可精确控 制墨滴的喷出过程从而获得较高的印刷精度. 压电 式喷头在石墨烯导电墨水的喷墨印刷研究中使用较 为广泛.

喷墨印刷的过程主要分为 3 个阶段: (1) 墨滴从 喷头中喷出, (2) 墨滴下落至承印基底, (3) 墨滴在承 印基底上固化. 在喷墨印刷图案化电路的过程中, 墨 水喷头移动到期望印刷的地点, 墨水微液滴从墨腔 顺着喷头喷出后飞溅至承印基底上, 众多墨水微墨 滴在基底上聚合形成图案化的液体薄膜. 随着墨水 中溶剂蒸发或渗透人承印基底或溶剂中的小分子交 联固化, 功能化墨水在承印基底上固化形成固态图 案. 上述 3 个阶段中, 喷墨印刷墨水的物理性能参数, 如黏度、密度和表面张力, 对印刷效果有很大影 响 ${ }^{[84]}$. 同样, 承印基底的温度、形貌和材质也对其有 显著影响 ${ }^{[41]}$, 对承印基底进行表面预处理 ${ }^{[85]}$ 有益于 提升印刷质量. 采用分散浓度较高的石墨烯墨水进 行喷墨印刷时, 挥发干燥过程中易出现由内至外石 墨烯层片堆积逐渐变厚的现象, 即咖啡环效应 ${ }^{[86]}$. 咖啡环效应会影响印刷质量, 降低印刷电路的电学 性能稳定性. 针对以上现象, 已有一系列的研究解决

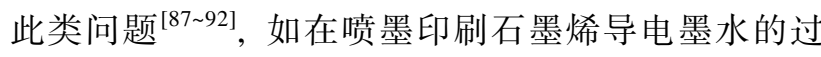
程中, 探究承印硅基底的表面状态对印刷效果的影 响. 研究表明, 采用酒精/松油醇分散的石墨烯导电 墨水, 在常温下的硅基底 $\left(25^{\circ} \mathrm{C}\right)$ 上干燥时, 松油醇与 硅基底的浸润性差、酒精与松油醇挥发速度相差较 大，导致干燥后的石墨烯层片无法均匀分散，产生咖 啡环效应. 在 $60^{\circ} \mathrm{C}$ 加热环境下干燥时, 松油醇干燥速 度增加, 接触角增大, 有效地抑制了咖啡环效应, 印 刷的图案更加均匀 ${ }^{[41]}$.

喷墨印刷是石墨烯导电墨水研究中应用最为广 泛的一种印刷工艺, 近年来发展较快, 但印刷精度仍 需进一步提升. 提升印刷精度的方法包括精确控制 喷出液滴、降低喷头尺寸以获得体积更小的墨滴等. 喷墨印刷墨水中固态颗粒的尺寸应小于喷墨喷头尺寸 
的 $1 / 15$, 否则容易堵塞喷头, 因此石墨烯层片大小受 制于喷头尺寸，对提升喷墨印刷精度有一定的挑战.

\section{2 川版印刷}

凹版印刷技术指通过一定工艺将印版表面形成 不同容积的凹穴(即着墨孔), 印刷时整个印版表面涂 满墨水, 刮刀刮去印版空白部分墨水的同时将墨水 充分挤人凹穴中, 再由压印装置将凹穴内蓄积的墨 水转移至承印物, 从而实现图文的转印. 其工艺特点 是与基底受压的为非图案化部分, 图案化部分基本 不受力, 因此凹版印刷的墨膜较厚. 柔性电子器件 中, 常用的丝网印刷工艺也属于凹版印刷的一种, 其 印版为丝网状, 因此适用于非平整印刷基底, 如球形 基底等. 凹版印刷是柔性电子器件制备研究中非常 实用的一种印刷技术, 可实现高分辨率、高速率印刷, 且兼容卷对卷工艺.

在印刷过程中, 低黏度墨水在转印时易发生扩 散, 从而严重降低印刷分辨率; 另外, 低浓度石墨烯 导电墨水要重复多次才能获得所需的电学性能, 会 严重影响印刷效率. 因此, 凹版印刷所用的石墨烯导 电墨水应同时具有高黏度和高浓度. 因石墨烯在常 见溶剂中分散性不佳, 所以石墨烯导电墨水在凹版 印刷中应用较少. Secor等人 ${ }^{[5,20]}$ 采用超声剥离法在乙 基纤维素/乙醇中制备了石墨烯分散液, 通过溶剂替 换法制备了以松油醇为溶剂, 乙基纤维素为辅助分 散剂的高浓度、高黏度的石墨烯导电墨水, 浓度最高 为 $20 \mathrm{mg} / \mathrm{mL}$, 黏度为 $10 \sim 15 \mathrm{mPa} \mathrm{s}$, 并且首次成功应 用于丝网印刷. 通过优化凹版印刷着墨孔的尺寸和 间距、印刷速度等工艺参数使凹版印刷的分辨率达到 $30 \mu \mathrm{m}$. 进一步, Hyun等人 ${ }^{[93]}$ 采用光刻硅片作为印版, 对凹版印刷的工艺参数进行了系统优化, 将丝网印 刷石墨烯导电墨水的分辨率提升至 $5 \mu \mathrm{m}$.

\section{3 转移印刷}

转移印刷(transfer printing)是将原本沉积于某种 基底上的材料, 通过某种方式再转移到另一种基底 上. 转移印刷按转移方式可分为直接移印和间接移 印. 直接移印的原理与凹版印刷相似, 当印版的分辨 率缩小至微纳米级, 则为微接触印刷术. 印刷模板一 般通过光学或电子束光刻等方法制备, 压模材料的 前驱体(如PDMS)在模板中固化后脱离构成压模, 在 压模的凹穴上附着功能墨水并刮除空白部分的墨水,
利用压力将凹穴内的墨水转移至基底上. 直接移印 具有设备要求低、多类型基底适用、操作方法灵活多 变等优点, 但浸墨及印刷过程需要优化, 以降低扩散 效应. 间接移印需要中间转印载体, 一般分为 4 个过 程: (1) 待转移的功能材料或墨水在原始基底上生长 或沉积完毕; (2) 选择某种特殊的中间转印载体(一般 采用柔性高聚物) 将功能材料从原始基底上剥离开 来; (3) 将承载着功能材料的中间转印载体转移至承 印基底上，通过一定方法将功能材料附着于承印基 底上; (4) 将中间转印载体与功能材料剥离. 对最后 2 个过程来说, 环境的温度和压力控制对实现无缺陷 印刷至关重要, 同时功能材料或功能墨水的质量也 对印刷效果有着巨大影响.

转移印刷与卷对卷印刷工艺兼容, 适用于不规 则起伏或不适宜利用印刷机进行印刷的基底，包括 三维物体或人类皮肤等. 转移印刷技术最大的优势 在于印刷图案精度较高, 分辨率可达 $100 \mathrm{~nm}^{[94]}$, 且 可用于印刷多种功能性材料, 如富勒烯 ${ }^{[94]}$ 、碳纳米 管 ${ }^{[95]}$ 等碳纳米材料, 生物高分子 $\mathrm{DNA}^{[96]}$, 半导体纳 米线 ${ }^{[97]}$ 、苂光材料 ${ }^{[98]}$ 、金属材料 ${ }^{[99]}$ 等.

转移印刷的效果受基底材料和中间转印载体材 料性质的影响, 也与印刷环境温度、气氛及压力等参 数相关. 通过调控以上参数, 可改变墨水与不同基底 的结合力. 当墨水与中间转印载体的结合力大于与 原始基底的结合力, 且小于与承印基底的结合力时, 转移印刷具有良好的印刷品质. 采用极性溶剂可有 效调控基底之间的结合力, Hines等人 ${ }^{[100]}$ 利用氟硅烷 蒸发时产生的毛细力, 有效转移了碳纳米材料印刷 图案中的微小结构, 将转移印刷的印刷分辨率提升 至 $100 \mathrm{~nm}$. Choi等人 ${ }^{[21]}$ 提出了一种快速、简单、有效 的转移印刷方法用于制备图案化石墨烯导电线路. 基于热膨胀失配原理, 借助“加热-冷却法”转移印刷 方法可以高效、高分辨率地将图案化的石墨烯层片精 确地定位在各种基底上, 石墨烯层片的转移率较无 热处理的传统转移印刷工艺提升了 $27 \%$ 90\%. 转移 印刷技术不仅可用于印刷石墨烯导电墨水，也可将 化学气相沉积(CVD)等方法制备的石墨烯薄膜转移 至目标基底, 并用于组装电子器件.

\section{4 笔画法}

印刷电子制造本质上是一种增材制造方法, 即 通过一定方法将功能性材料图案化沉积在目标基底 
上. 对于小批量、个性化定制的制备, 笔画法(directwriting) 是最为简单便捷的快速成形方法之一 ${ }^{[101]}$. 笔 画法是通过相互作用力将功能材料从书写工具转移 至期望基底, 优点在于快速成形、低成本、低消耗、 净成形、可平行集成多种不同类型的功能性材料, 如 金属材料 ${ }^{[102]}$ 、高聚物材料 ${ }^{[103]}$ 、碳纳米材料 ${ }^{[104]}$ 及半 导体材料 ${ }^{[105]}$. 其中, 功能性材料在沉积过程中, 一 般不经过温度或化学上的环境变化, 性质一般不会 受到影响. 同时, 笔画法相对于其他印刷方法, 可兼 容更多类型的基底, 如粗糙基底(纸、布料、硬币等) 和光滑基底(高聚物、金属、玻璃等). 对于一些不易 于直接印刷的基底, 如人类皮肤, 笔画法也有很好的 兼容. 基于以上优点, 笔画法适用于设计与制造不同 类型的可穿戴柔性设备, 如可穿戴功能检测器件、皮 肤接触式医疗检测器件等.

目前使用的笔画法工具主要有毛笔、铅笔、钢笔 和原子笔4种, 不同书写工具的成型工艺特点不同, 所需的导电墨水性能参数也不同 ${ }^{[101]}$. 笔画法也可分 为液态书写和固态书写两大类. 液态书写指通过钢 笔等工具书写液态导电墨水, 墨水通过溶剂挥发或 者交联等方法固化. 固态书写指将功能性材料制作 为固态书写工具, 可以避免溶剂挥发的影响, 实现环 境友好的无溶剂制造. 二者的力学成形机制并不相 同. 由于固态书写的过程是功能材料的转移过程, 也 是机械剥离的过程, 因此固态书写的基底一般限制 于具有表面粗楉度的基底, 如纸类 ${ }^{[106]}$. 液态书写过 程主要与导电墨水在基底上的润湿性相关, 可适用 的基底范围更广. 笔画法的工艺参数主要包括书写 速度与重复书写次数, 书写速度较高时容易形成不 连续的墨膜, 而书写速度较低时容易形成不均匀的 墨膜. 一般而言, 书写速度控制在1 2 $\mathrm{cm} / \mathrm{s}$ 时可以获 得较好的书写质量 ${ }^{[101]}$. 重复书写次数对墨膜的物理 导电性能有一定影响. 墨膜的方阻随重复书写次数 的增加而降低, 同时墨膜的密度与力学参数也有一 定变化. 书写重复次数与生产时间直接相关, 因此电 学性能与时间成本需综合考虑.

目前, 许多柔性器件可以实现一定程度上的弯 折或扭转, 但是完全折叠会对其性能造成大幅度衰 减. Hyun等人 ${ }^{[107]}$ 通过笔画方法将原本沉积于聚四氟 乙烯(polytetrafluoroethylene, PTFE)真空抽滤膜的石 墨烯膜通过笔画法施加压力而转移至打印纸基底上, 形成柔性可折叠的导电线路(图4(a)). 通过笔画法制
备的石墨烯导电线路具有很好的力学稳定性, 在弯 折甚至完全折叠状态下都具有良好的电学性能. 在 笔画法制备功能性器件的研究中, 石墨烯一方面可 作为导电基材辅助其他功能性材料实现功能化电路, 如分子嗅探等. Mirica等人 ${ }^{[104]}$ 用石墨片与化学嗅探 分子通过球磨及锻压法制备了无溶剂的类铅笔芯, 并将其画在蒸镀有银电极的纸上, 搭建了可以有效 检测各种化学分子的传感器. 另一方面, 石墨烯本身 可作为功能性材料实现一定的功能, 如力学传感等. Liao等人 ${ }^{[22]}$ 通过在纸基底上直接书写石墨片构成的 功能性电路, 制备了一种柔性可弯折的力学传感器, 用于检测人体微运动. 在功能性电路中, 石墨层片在 应力作用下实现了搭接和脱离过程, 而层片的接触 状态直接影响了电流传导, 因此可以通过检测电阻 来检测应变的发生.

\subsection{D打印}

3D打印技术是一种快速成形的增材制造技术， 通过逐层印刷的方法将可黏合的材料构建为 $3 \mathrm{D}$ 物体. 不同材料具有不同的逐层印刷方式，主要包括熔融 沉积式、烧结成形式、光聚合式等技术. 最常见的制 备工艺为熔融沉积式, 即功能化墨水从喷头挤出后 沉积在基底上, 通过多次重复此过程逐层印刷出具 有 $3 \mathrm{D}$ 结构的实体. $3 \mathrm{D}$ 打印具有接近净成形、单件试制 成本低等优势，因而广泛应用于不同领域，如能源领 域的超级电容器 ${ }^{[110]}$ 、微型锂电池 ${ }^{[111]}$, 生物领域的组 织工程支架 ${ }^{[12]}$ 、人工神经 ${ }^{[113]}$, 以及工程领域的应力 传感器 ${ }^{[114]}$ 等.

3D打印的固化过程对提高打印精度和质量至关 重要, 因此防止墨水液滴铺展与加速墨水固化是提 升3D打印应用研究中的重要课题. 目前, 通过3D打 印技术构建的电路的精度最高达到约 $10 \mu \mathrm{m}^{[115]}$. 为 了提高印刷精度与质量, 用于 $3 \mathrm{D}$ 打印的石墨烯导电 墨水应具有特定的印刷适性, 一般通过添加黏度高 且挥发速度较高、沸点较低的有机溶剂进行改性. 采 用紫外线照射迅速固化也是一个研究方向. 为了保 证重复印刷时后一层与前一层黏结牢固, 墨水固化 的速度不能太快, 否则会导致结构的脱离. 因此, 可 以通过添加一些保湿剂来辅助保证印刷精度. 合理 调整石墨烯导电墨水的印刷适性同时保证其优良力 学、电学性能的研究将是3D打印应用于石墨烯导电 墨水的重点 ${ }^{[111]}$. 
(a)

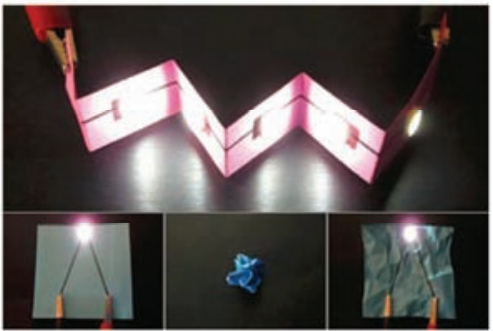

(d)

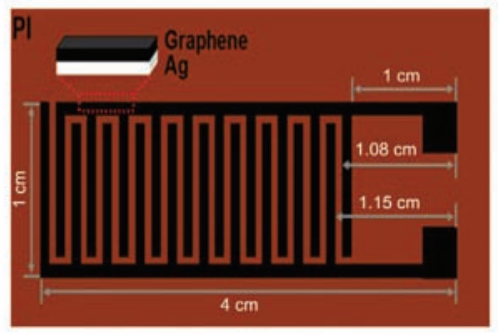

(g)

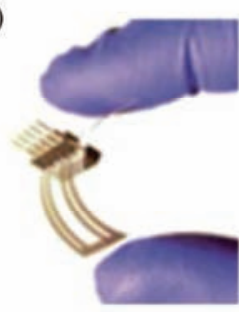

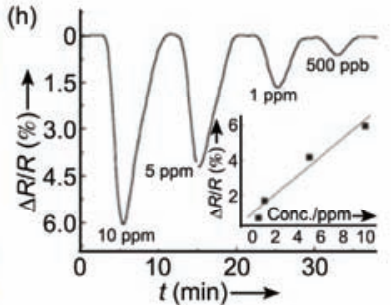

(b)

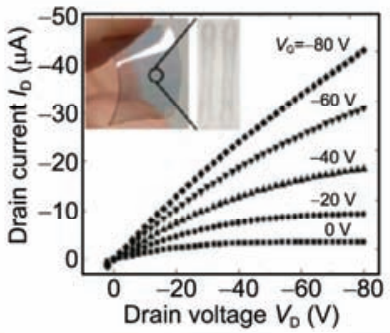

(e)

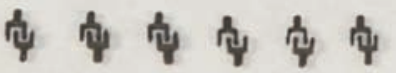

(c)
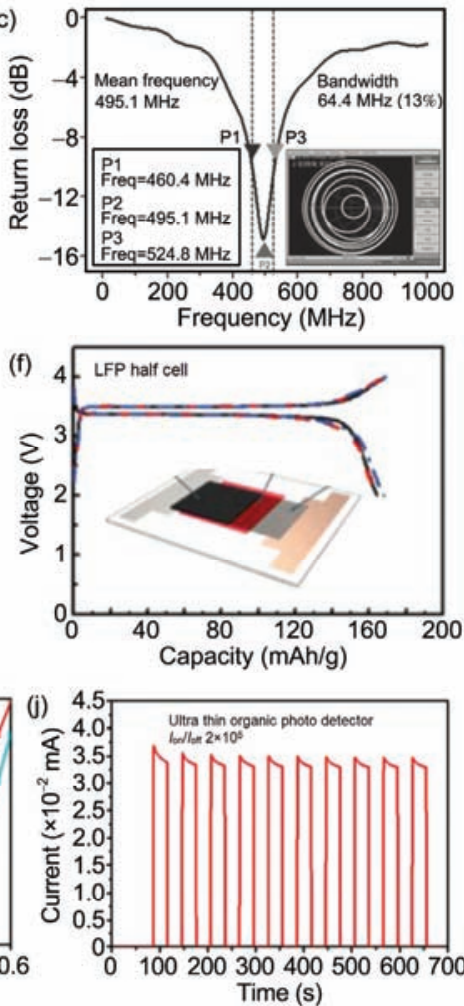

图 4 (网络版彩色)石墨烯导电墨水的应用. 基础电路元件类应用: (a) 可折叠石墨烯导电线路 [107]; (b) 柔性场效应晶体管(field-effect transistor, FET)的输出特恃 ${ }^{[68]}$; (c) 偶极天线的回波损耗曲线, 插图为阻抗图 ${ }^{[63]}$. 能源类应用: (d) 印刷柔性微电容器(MSC)结构示意图 ${ }^{[108]}$; (e) 3D印刷的 锂电池; (f) $10 \mathrm{~mA} / \mathrm{g}$ 特定电流密度下, 印刷锂电池的充放电曲线, 插图为平板型锂电池的结构示意图 ${ }^{[109]}$. 传感类应用: (g) 柔性气体传感器; (h) 对 $\mathrm{NO}_{2}$ 的响应, 插图为电阻对蒸汽浓度的曲线图 ${ }^{[66]}$; (i) 柔性PET基底的有机光电检测器件(OPD)的伏安特性曲线. 插图为 $\mathrm{OPD}$ 器件实物图与结 构示意图 ${ }^{[77]}$; (j) 超薄光电探测器开关比特性 ${ }^{[77]}$

Figure 4 (Color online) Applications of graphene inks. (a) Foldable graphene electronic circuits ${ }^{[107]}$. (b) Output characteristics of flexible FETs ${ }^{[68]}$. (c) Return loss curve of the dipole antenna application. Inset: Smith chart impedance diagram of the calculated dipole antenna ${ }^{[63]}$. (d) Schematic diagram of $\mathrm{MSC}^{[108]}$. (e) Digital image of 3D-printed electrode arrays. (f) Charge and discharge profiles of the LFP/rGO half-cell at a specific current density of 10 $\mathrm{mA} / \mathrm{g}$. Inset: Schematic of the planar battery ${ }^{[109]}$. (g) Inkjet-printed rGO/PET four-probe vapor sensor. (h) Plot of resistance versus time for inkjet-printed $\mathrm{rGO} / \mathrm{PET}$ when exposed to $\mathrm{NO}_{2}$. Inset: Plot for resistance versus vapor concentration ${ }^{[66]}$. (i) $I-V$ characteristics of the photodetectors fabricated on regular PET. Inset: The fabricated device and schematic structure of OPDs. (j) On/off characteristics of the ultrathin photodetectors ${ }^{\text {[77] }}$

石墨烯具有优良的电学、力学性能, 因此石墨烯 与高聚物或陶瓷的复合材料具有良好的综合性能. Roman-Manso等人 ${ }^{[116]}$ 通过3D打印技术将 $\mathrm{SiC}$ 陶瓷粉 末与石墨烯的复合油墨组装为轻质3D蜂窝结构材料, 经放电等离子体烧结后, 该材料具有小于 $1.6 \mathrm{~g} / \mathrm{cm}^{3}$ 的低密度、良好的抗碎强度和各向异性的电导率, 纵 向电导率高达 $611 \mathrm{~S} / \mathrm{m}$, 横向电导率为 $273 \mathrm{~S} / \mathrm{m}$. 同时, $3 \mathrm{D}$ 打印可对材料进行结构设计, Zhu等人 ${ }^{[117]}$ 利用 $3 \mathrm{D}$ 打印技术将石墨烯导电墨水构建为弹塑性能优秀的 $3 \mathrm{D}$ 网络状导电材料. 在进一步研究中, 对材料结构 进行了优化, 制备了具有周期性大孔的导电材料, 适 于制备超级电容器 ${ }^{[23]}$. 在迅速固化方面的研究中, Zhang等人 ${ }^{[118]}$ 提出 “低温法”用于打印石墨烯凝胶,
该凝胶具有优良的电学力学性能, 电导率 $15.4 \mathrm{~S} / \mathrm{m}$, 密度达到 $0.5 \sim 10 \mathrm{mg} / \mathrm{cm}^{3}$, 同时具有良好的可压缩性.

特别地, 当采用的高聚物具有一定生物相容性 时, 石墨烯导电墨水可用于再生医学与组织工程领域. 2015 年, Jakus等人 ${ }^{[113]}$ 提出 “可 3D 打印石墨烯 (3D printable graphene, 3DG)”, 其主体为石墨烯, 辅助料 为聚乳酸-乙醇酸 (polylactide- $c o$-glycolide), 可直接 用于 $3 \mathrm{D}$ 打印, 并能打印出最细宽度为 $100 \mu \mathrm{m}$, 最少 2 层最多数百层的物体, 其厚度在 $300 \mu \mathrm{m} 10 \mathrm{~cm}$. 该 材料具有稳定的力学性能, 具有一定柔性, 电导率为 $800 \mathrm{~S} / \mathrm{m}$. 由于聚乳酸-乙醇酸具有生物相容性, 人骨 髓间充质干细胞相容可在3D打印结构上稳定攀附、 生长、繁殖和扩散，在人类神经细胞模型方面具有广 
阔应用前景. Jakus和Shah ${ }^{[19]}$ 将石墨烯应用于修饰羟 基磷灰石, 制备的复合材料墨水通过3D打印可以制 备修复骨结构的生物工程材料.

\section{3 石墨烯导电墨水的应用}

采用印刷石墨烯导电墨水或水平集成不同功能 性墨水, 可制备许多不同类型的印刷电子器件, 并应 用于不同领域. 这些应用主要分为 3 大类: (1) 导电线 路、场效应晶体管、射频电路等基本电路元器件; (2) 微型超级电容器、锂电池等能源存储器件; (3) 力学 传感、化学传感等传感器. 通过对于石墨烯导电墨水 参数以及印刷工艺的调控, 可以实现不同应用(图4).

\section{1 基本电路}

导电线路是基本电路构成中最基础的元器件. 因此, 石墨烯导电墨水研究的主要目标是获得分辨 率更高、电导率更好的导电线路. 在印刷工艺中经常 使用的基底包括纸、PET, PI，玻璃等. Huang等人 ${ }^{[62]}$ 在纸、PET, PI基底上喷墨印刷GO水分散液, 通过在 惰性气体环境、 $400^{\circ} \mathrm{C}$ 还原 $3 \mathrm{~h}$ 后, 获得了具有良好电 导率的印刷图案, 成功点亮了LED灯. Sinar等人 ${ }^{[71]}$ 在 玻璃和柔性聚合物基底上喷墨印刷羧甲基纤维素辅 助分散的石墨烯水性墨水, 激光退火后, 获得方阻为 $100 \Omega / \mathrm{sq}$ 的透明薄膜. Gao等人 ${ }^{[120]}$ 利用乙基纤维素辅 助分散的石墨烯墨水, 经过30次喷墨印刷后, 其电阻 率为 $0.81 \pm 0.2 \mathrm{k} \Omega / \mathrm{sq} .300^{\circ} \mathrm{C}$ 退火 $30 \mathrm{~min}$ 后, 印刷图案 具有 $9.24 \times 10^{3} \mathrm{~S} / \mathrm{m}$ 的高电导率, 且具有良好力学稳定 性, 电阻率在 1000 次弯曲循环后的增加小于 $5 \%$, 在 $180^{\circ}$ 的折叠角度下仅增加 $5.3 \%$. Wan等人 ${ }^{[121]}$ 通过喷 墨印刷方法印刷钠离子增强 $\mathrm{rGO}$ 导电墨水, 构建了可 应用于柔性功能器件的透明电极. Georgakilas等 人 $^{[122]}$ 通过亲水型碳纳米管辅助掺杂的石墨烯水分散 液, 构建了低电阻的导电电路. Jakus等人 ${ }^{[113]}$ 用3D打 印技术构建了具有生物相容性的导线, 在生物组织 工程领域具有一定的应用潜力.

薄膜晶体管(thin film transistor, TFT) 和FET也是 集成电路中重要的组成部分, 柔性晶体管是在柔性 功能器件中有重要应用的一种基本元件. 2012年, $\mathrm{Lim}^{\text {等人 }}{ }^{[68]}$ 采用 GO 和PVA复合导电墨水在塑料基材 上通过喷墨印刷方法制备了柔性FET(图4(b)), 经过 化学和热还原后, 其场效应迁移率达到 $0.23 \mathrm{~cm}^{2} /(\mathrm{V}$ $\mathrm{s})$, 比同等条件下金电极或PEDOT:PSS电极的FET
有所增强. Torrisi等人 ${ }^{[19]}$ 将NMP液相剥离的石墨烯层 片用于喷墨印刷, 印刷图案的方阻为 $30 \mathrm{k} \Omega / \mathrm{sq}$, 透光 率约 $80 \%$, 组装的晶体管迁移率约 $95 \mathrm{~cm}^{2} /(\mathrm{V} \mathrm{s})$. 在晶 体管制备中, 印刷图案的电阻率对迁移率具有重要 影响.

石墨烯导电墨水也可用于射频研究. Shin等人 ${ }^{[63]}$ 在柔性高聚物基材 $\mathrm{PET}$ 上喷墨印刷了 GO 水分散液, 并在 $90{ }^{\circ} \mathrm{C}$ 下利用水合肼蒸汽进行还原. 所制备的高 分辨率的印刷图案具有良好的导电率, 可用作宽频 带天线 (图 4(c)), 其带宽为 $500 \mathrm{MHz}$, 传输效率为 96.7\%. 柔性无线传输电路对制备柔性可穿戴器件具 有重要应用价值.

\section{2 能源存储}

基于石墨烯的优良性质, 如高比表面积、高电导 率、低吸光率等, 石墨烯导电墨水在能源存储器件中 有广泛的应用 ${ }^{[123,124]}$. 相对传统能源存储器件, 超级 电容器具有高功率密度、高充放电速率、工作温度范 围广等优点, 特别是微型超级电容器 (microsupercapacitor, MSC) 在移动可穿戴设备中具有重要的应用 价值, 如无线传感系统、压电发电器件等. 2011年, Le 等人 ${ }^{[61]}$ 首次通过喷墨印刷 $\mathrm{GO}$ 分散液后热还原的方式 构建了超级电容器, 在金属集流体上喷墨印刷了 $0.2 \%$ (质量百分比)的 $\mathrm{GO}$ 水分散液, 并在 $\mathrm{N}_{2}$ 气氛中 $200^{\circ} \mathrm{C}$ 热还原处理 $12 \mathrm{~h}$, 其电容值达到 $132 \mathrm{~F} / \mathrm{g}$. Ervin 等人 ${ }^{[125]}$ 用Kapton作为集流体, 将电容值进一步提升 至192 F/g. 石墨烯导电墨水与其他材料, 如金属纳 米材料、半导体材料和高聚物材料等, 共同用于印刷 的超级电容器, 有效提升了超级电容器的性能参数. $\mathrm{Li}$ 等人 ${ }^{[41]}$ 制备了一种全印刷超级电容器, 用银纳米 颗粒印刷集流体, 石墨烯印刷电极. 在 $\mathrm{NaSO}_{4}$ 水溶液 环境下, 扫描速率为 $100 \mathrm{mV} / \mathrm{s}$ 时, 面电容为 0.19 $\mathrm{mF} / \mathrm{cm}^{2}$. 随着石墨烯印刷次数的增加, 电容量也随 之增加. Kelly等人 ${ }^{[126]}$ 提出了石墨烯/六方氮化硼 (h-BN)/石墨烯堆叠结构, 其制备的介电电容器面电 容为 $0.24 \sim 1.1 \mathrm{nF} / \mathrm{cm}$, 平均串联电阻为 $120 \mathrm{k} \Omega$. 这种 堆叠结构结合喷墨印刷与喷涂 2 种工艺制备, 具有进 一步深人研究的价值. PANI是一种具有优良电化学 性能的高聚物材料, 但循环稳定性差且电阻值偏高. $\mathrm{Xu}$ 等人 ${ }^{[78]}$ 制备了石墨烯与PANI的复合导电墨水，在 碳纤维基底上通过喷墨印刷方法制备了电极, 构建 了具有三明治结构的超级电容器. 在 $\mathrm{H}_{2} \mathrm{SO}_{4}$ 水溶液 
中, 其电容值达到 $82 \mathrm{~F} / \mathrm{g}$, 且循环稳定性优良. Zhang 等人 ${ }^{[108]}$ 用 $\mathrm{Mg}(\mathrm{OH})_{2}$ 插层的石墨烯导电油墨, 通过凹 版印刷的方法在柔性PI基底上制备了微型电容器(图 4(d)), 其面电容值达到 $6.65 \mathrm{mF} / \mathrm{cm}^{2}$, 在功率密度为 25 $\mathrm{mW} / \mathrm{cm}^{3}$ 时能量密度达到 $1.41 \mathrm{~mW} \mathrm{~h} / \mathrm{cm}^{3}$. 其中, $\mathrm{Mg}(\mathrm{OH})_{2}$ 作为纳米间隔物加剧石墨烯层片的碎裂并防 止其重新堆叠, 增加电化学活性区域面积和含氧基团 数量. 锂电池是如今应用最为广泛的一种电池, 将石 墨烯与其他材料结合制备的复合导电墨水可用于制备 性能优秀的锂电池. 近期, Fu等人 ${ }^{[109]}$ 通过3D打印石墨 烯复合油墨和固态凝胶聚合物电解质制备了高性能锂 电池(图4(e), (f)), 电极担载量达到了 $18 \mathrm{mg} / \mathrm{cm}^{2}$.

\section{3 传感}

石墨烯的比表面积和电学性能在力学传感、化学 传感等方面都有应用. 目前有很多基于石墨烯导电 墨水的力学传感器件的研究, 石墨烯片层之间的微 观搭接结构是其作为基础力敏单元的基本. Hempel 等人 ${ }^{[127]}$ 通过在PET基底上喷涂石墨烯导电墨水, 快 速制备了一种应力传感器, 其响应机理可以通过逾 渗理论模拟与解释. Chen等人 ${ }^{[128]}$ 将基于层片微观搭 接状况的应力传感器称为 “渝渗应力传感器”, 探究 了石墨烯薄膜的初始电阻、石墨烯层片尺寸和薄膜形 貌对传感器灵敏性和循环稳定性的影响.

石墨烯导电墨水同样可应用于温度传感器中, 2012年, Kong 等人 ${ }^{[58]}$ 通过喷墨印刷GO水分散液后, 在红外加热灯下直接还原, 得到电导率最低为 0.3 $\mathrm{M} \Omega / \mathrm{sq}$, 透光性为 $86 \%$ 的导电薄膜. 由于其具有负温 度系数特性, 因此可作为温度传感器, 且比传统负温 度系数材料有更快的响应时间.

在化学传感方面, 石墨烯导电墨水可用于气体 传感与电化学传感 ${ }^{[129]}$. Dua等人 ${ }^{[66]}$ 通过在PET基底上 喷墨印刷 $\mathrm{rGO}$ 分散液制备了一种快速气体检测器件 (图 4(g), (h)), 实现了空气中对 $\mathrm{NO}_{2}$ 和 $\mathrm{Cl}_{2}$ 的 $\mathrm{ppb}$ (parts per billion)级检测. Bardpho等人 ${ }^{[130]}$ 在碳电极上丝网 印刷或喷墨印刷石墨烯-聚苯胺(G/PANI)复合导电油 墨, 用于增强碳电极对多酚抗氧化剂的检测灵敏度. 结合反相超高效液相色谱, 该电化学传感器在 $3 \mathrm{~min}$ 内成功分离并识别了 4 种抗氧化剂, 且抗氧化剂的线 性校准和检测限 $(S / N=3)$ 达到了 $0.01 \sim 10 \mu \mathrm{g} / \mathrm{mL}$ 和 $1.38 \sim$ $1.94 \mathrm{ng} / \mathrm{mL}$. Wang 等人 ${ }^{[131]}$ 制备了乙基纤维素和 Nafion辅助分散的石墨烯导电墨水, 利用电流体动力
学喷墨方法在玻璃及聚二甲基硅氧烷(PDMS)上制备 了电化学检测器件, 用于铅离子的检测, 其检测效率 优于纯铂电极.

在光电检测方面, 2014年, Finn等人 ${ }^{[132]}$ 将液相剥 离的石墨烯与二硫化钼配置为高浓度 $(6 \mathrm{mg} / \mathrm{mL})$ 的复 合导电墨水, 低于 $70^{\circ} \mathrm{C}$ 条件下喷墨印刷后无需热处 理或化学处理, 当印刷线条厚度大于 $160 \mathrm{~nm}$ 时, 印刷 图案的电导率为 $3 \times 10^{3} \mathrm{~S} / \mathrm{m}$, 并制备了全印刷的光电 检测器件. 2015年, Liu等人 ${ }^{[77]}$ 通过喷涂方法用石墨烯/ PEPOT : PSS复合导电墨水制备了大面积透明导电薄 膜, 其导电率为 $1 \times 10^{5} \mathrm{~S} / \mathrm{m}$, 透光率在 $500 \mathrm{~nm}$ 波段时 约 $80 \%$. 导电薄膜同时具有良好的力学性能, 作为底 部电极组装为超薄有机光电探测器(图4(i), (j)), 其检 测效率与现有硅基底的无机光电探测器件相似.

生物传感方面, Wisitsoraat等人 ${ }^{[133]}$ 综述了有机官 能化石墨烯在印刷生物传感器技术方面的应用, 通 过FET, 计时安培分析法等检测方法, 可实现对葡萄 糖、胆固醇、儿茶酚、双氧水、DNA, 癌胚抗原 (CEA)、 甲胚蛋白(AFP)等物质的高精度分析.

\section{4 总结与展望}

近年来, 随着柔性电子器件应用规模的日益扩 大, 低成本、大批量制备定制化的柔性可穿戴电子器 件具有重要意义. 印刷电子技术可在多种基底(金 属、陶瓷、聚合物或生物皮肤等)上平行集成多种材 料的任意图案, 对于制备柔性移动医疗器件、人机交 互器件等柔性可穿戴设备具有独特优势. 石墨烯具 有独特的二维结构和优良的光学、电学、力学性能, 在微电子器件领域具有广阔的应用前景. 通过印刷 石墨烯导电墨水可在多种类型的基底上快速完成图 案化导电薄膜的制备, 并进一步组装为功能性电子 器件. 基于石墨烯导电墨水的电子印刷技术与现代 微电子制造技术相互补充且相互兼容, 填补了大面 积柔性功能性器件的低成本个性化制造方面的空白. 基于石墨烯导电墨水的印刷电子研究成果数量逐年 上升, 是近期研究热点之一.

基于石墨烯导电墨水的柔性可穿戴电子器件已 尝试应用在能源存储器件、传感器件等领域. 石墨烯 与金属颗粒、高聚物分子、生物高分子等复合制备功 能性导电墨水, 其应用领域可进一步拓展. 石墨烯导 电墨水的制备与应用需深人研究. 首先, 基于石墨烯 导电墨水的印刷线路导电率需要进一步提升, 以满 
足精密微电子元件的需求. 其次, 石墨烯导电墨水的 浓度、稳定性、印刷适性和印刷效率尚有优化空间. 石墨烯导电墨水在凹版印刷方面的应用研究还相对 较少, 而与卷对卷印刷技术相兼容的凹版印刷可在 印刷柔性可穿戴设备中有更广泛的应用. 基于 $\mathrm{GO}$ 或 添加辅助分散剂的导电墨水印刷后需要后处理, 而 过于复杂的印刷后处理会限制石墨烯导电墨水的应 用, 因此, 开发便捷有效的GO印刷图案的还原方法
和表面活性剂的去除方法具有重要意义. 最后, 石墨 烯导电墨水的印刷工艺也需要优化, 一方面, 印刷分 辨率应进一步提升以满足电子器件的需求; 另一方 面, 印刷工艺对纳米材料功能性墨水应具有更好的 兼容性, 避免材料在印刷过程发生团聚、变质等影响 印刷器件性能的情况. 实现快速、高精度、工艺简 单、均匀且可控的印刷是石墨烯导电墨水应用的先决 条件.

\section{参考文献}

1 Torrisi F, Coleman J N. Electrifying inks with 2D materials. Nat Nanotechnol, 2014, 9: 738-739

2 Kamyshny A, Magdassi S. Conductive nanomaterials for printed electronics. Small, 2014, 10: 3515-3535

3 Hof F, Kampioti K, Huang K, et al. Conductive inks of graphitic nanoparticles from a sustainable carbon feedstock. Carbon, 2017, 111: 142-149

4 Kim J H, Lee S, Wajahat M, et al. Three-dimensional printing of highly conductive carbon nanotube microarchitectures with fluid ink. ACS Nano, 2016, 10: 8879-8887

5 Secor E B, Ahn B Y, Gao T Z, et al. Rapid and versatile photonic annealing of graphene inks for flexible printed electronics. Adv Mater, 2015, 27: 6683-6688

6 Liang J J, Tong K, Pei Q B. A water-based silver-nanowire screen-print ink for the fabrication of stretchable conductors and wearable thin-film transistors. Adv Mater, 2016, 28: 5986-5996

7 Lee C, Kim N R, Koo J, et al. Cu-Ag core-shell nanoparticles with enhanced oxidation stability for printed electronics. Nanotechnology, 2015, 26: 455601

8 Jason N N, Shen W, Cheng W L. Copper nanowires as conductive ink for low-cost draw-on electronics. ACS Appl Mater Interfaces, 2015, 7: 16760-16766

9 Guo Y, Otley M T, Li M, et al. PEDOT:PSS “wires” printed on textile for wearable electronics. ACS Appl Mater Interfaces, 2016, 8: 26998-27005

10 Fan X, Xu B, Liu S, et al. Transfer-printed PEDOT:PSS electrodes using mild acids for high conductivity and improved stability with application to flexible organic solar cells. ACS Appl Mater Interfaces, 2016, 8: 14029-14036

11 Bae E J, Kang Y H, Jang K, et al. Enhancement of thermoelectric properties of PEDOT:PSS and tellurium-PEDOT:PSS hybrid composites by simple chemical treatment. Sci Rep, 2016, 6: 18805

12 Yu Y, Xiao X, Zhang Y K, et al. Photoreactive and metal-platable copolymer inks for high-throughput, room-temperature printing of flexible metal electrodes for thin-film electronics. Adv Mater, 2016, 28: 4926-4934

13 Yang W D, Wang C H. Graphene and the related conductive inks for flexible electronics. J Mater Chem C, 2016, 4: 7193-7207

14 Choi H W, Zhou T, Singh M, et al. Recent developments and directions in printed nanomaterials. Nanoscale, 2015, 7: 3338-3355

15 Lawes S, Riese A, Sun Q, et al. Printing nanostructured carbon for energy storage and conversion applications. Carbon, 2015, 92: $150-176$

16 Novoselov K S, Geim A K, Morozov S V, et al. Electric field effect in atomically thin carbon films. Science, 2004, 306: 666-669

17 Novoselov K S, Jiang D, Schedin F, et al. Two-dimensional atomic crystals. Proc Natl Acad Sci USA, 2005, 102: 10451-10453

18 Secor E B, Hersam M C. Emerging carbon and post-carbon nanomaterial inks for printed electronics. J Phys Chem Lett, 2015, 6: 620-626

19 Torrisi F, Hasan T, Wu W P, et al. Inkjet-printed graphene electronics. ACS Nano, 2012, 6: 2992-3006

20 Secor E B, Lim S, Zhang H, et al. Gravure printing of graphene for large-area flexible electronics. Adv Mater, 2014, 26: 4533-4538

21 Choi M K, Park I, Kim D C, et al. Thermally controlled, patterned graphene transfer printing for transparent and wearable electronic/ optoelectronic system. Adv Funct Mater, 2015, 25: 7109-7118

22 Liao X, Liao Q, Yan X, et al. Flexible and highly sensitive strain sensors fabricated by pencil drawn for wearable monitor. Adv Funct Mater, 2015, 25: 2395-2401

23 Zhu C, Liu T Y, Qian F, et al. Supercapacitors based on three-dimensional hierarchical graphene aerogels with periodic macropores. Nano Lett, 2016, 16: 3448-3456 
Nair R R, Blake P, Grigorenko A N, et al. Fine structure constant defines visual transparency of graphene. Science, 2008, 320 : 1308

Mayorov A S, Gorbachev R V, Morozov S V, et al. Micrometer-scale ballistic transport in encapsulated graphene at room temperature. Nano Lett, 2011, 11: 2396-2399

Balandin A A. Thermal properties of graphene and nanostructured carbon materials. Nat Mater, 2011, 10: 569-581

King A, Johnson G, Engelberg D, et al. Observations of intergranular stress corrosion cracking in a grain-mapped polycrystal. Science, 2008, 321: 382-385

Stoller M D, Park S, Zhu Y, et al. Graphene-based ultracapacitors. Nano Lett, 2008, 8: 3498-3502

Li X, Cai W, An J, et al. Large-area synthesis of high-quality and uniform graphene films on copper foils. Science, 2009, 324: $1312-1314$

Huang X, Qi X, Boey F, et al. Graphene-based composites. Chem Soc Rev, 2012, 41: 666-686

Huang X, Yin Z, Wu S, et al. Graphene-based materials: Synthesis, characterization, properties, and applications. Small, 2011, 7: 1876-1902

Fan X, Peng W, Li Y, et al. Deoxygenation of exfoliated graphite oxide under alkaline conditions: A green route to graphene preparation. Adv Mater, 2008, 20: 4490-4493

Wang Z J, Zhou X Z, Zhang J, et al. Direct electrochemical reduction of single-layer graphene oxide and subsequent functionalization with glucose oxidase. J Phys Chem C, 2009, 113: 14071-14075

$\mathrm{Ng}$ Y H, Iwase A, Kudo A, et al. Reducing graphene oxide on a visible-light $\mathrm{BiVO}_{4}$ photocatalyst for an enhanced photoelectrochemical water splitting. J Phys Chem Lett, 2010, 1: 2607-2612

Mao S, Lu G H, Yu K H, et al. Specific protein detection using thermally reduced graphene oxide sheet decorated with gold nanoparticleantibody conjugates. Adv Mater, 2010, 22: 3521-3526

Vinodgopal K, Neppolian B, Lightcap I V, et al. Sonolytic design of graphene-Au nanocomposites. Simultaneous and sequential reduction of graphene oxide and Au(III). J Phys Chem Lett, 2010, 1: 1987-1993

Hummers W S, Offeman R E. Preparation of graphitic oxide. J Am Chem Soc, 1958, 80: 1339

Fernandez-Merino M J, Guardia L, Paredes J I, et al. Vitamin C is an ideal substitute for hydrazine in the reduction of graphene oxide suspensions. J Phys Chem C, 2010, 114: 6426-6432

Kumar P V, Bardhan N M, Tongay S, et al. Scalable enhancement of graphene oxide properties by thermally driven phase transformation. Nat Chem, 2014, 6: 151-158

Hernandez Y, Nicolosi V, Lotya M, et al. High-yield production of graphene by liquid-phase exfoliation of graphite. Nat Nanotechnol, 2008, 3: 563-568

Li J, Ye F, Vaziri S, et al. Efficient inkjet printing of graphene. Adv Mater, 2013, 25: 3985-3992

Secor E B, Prabhumirashi P L, Puntambekar K, et al. Inkjet printing of high conductivity, flexible graphene patterns. J Phys Chem Lett, 2013, 4: 1347-1351

Secor E B, Smith J, Marks T J, et al. High-performance inkjet-printed indium-gallium-zinc-oxide transistors enabled by embedded, chemically stable graphene electrodes. ACS Appl Mater Interfaces, 2016, 8: 17428-17434

Wang J, Manga K K, Bao Q, et al. High-yield synthesis of few-layer graphene flakes through electrochemical expansion of graphite in propylene carbonate electrolyte. J Am Chem Soc, 2011, 133: 8888-8891

Lu J, Yang J X, Wang J Z, et al. One-pot synthesis of fluorescent carbon nanoribbons, nano-particles, and graphene by the exfoliation of graphite in ionic liquids. ACS Nano, 2009, 3: 2367-2375

Guo H, Wang X, Qian Q, et al. A green approach to the synthesis of graphene nanosheets. ACS Nano, 2009, 3: 2653-2659

Parvez K, Li R J, Puniredd S R, et al. Electrochemically exfoliated graphene as solution-processable, highly conductive electrodes for organic electronics. ACS Nano, 2013, 7: 3598-3606

Parvez K, Wu Z S, Li R J, et al. Exfoliation of graphite into graphene in aqueous solutions of inorganic salts. J Am Chem Soc, 2014, 136: 6083-6091

Ejigu A, Kinloch I A, Dryfe R A W. Single stage simultaneous electrochemical exfoliation and functionalization of graphene. ACS Appl Mater Interfaces, 2017, 9: 710-721

Choucair M, Thordarson P, Stride J A. Gram-scale production of graphene based on solvothermal synthesis and sonication. Nat Nanotechnol, 2009, 4: 30-33

Deng D, Pan X, Yu L, et al. Toward N-doped graphene via solvothermal synthesis. Chem Mater, 2011, 23: 1188-1193

Han X, Chen Y, Zhu H, et al. Scalable, printable, surfactant-free graphene ink directly from graphite. Nanotechnology, 2013, 24: 205304

Georgakilas V, Tiwari J N, Kemp K C, et al. Noncovalent functionalization of graphene and graphene oxide for energy materials, biosensing, catalytic, and biomedical applications. Chem Rev, 2016, 116: 5464-5519 
54 Wei D, Li H, Han D, et al. Properties of graphene inks stabilized by different functional groups. Nanotechnology, 2011, 22: 245702

55 Li L, Guo Y, Zhang X, et al. Inkjet-printed highly conductive transparent patterns with water based Ag-doped graphene. J Mater Chem A, 2014, 2: 19095-19101

56 Stankovich S, Dikin D A, Dommett G H B, et al. Graphene-based composite materials. Nature, 2006, 442: 282-286

57 Paredes J I, Villar-Rodil S, Martinez-Alonso A, et al. Graphene oxide dispersions in organic solvents. Langmuir, 2008, 24: 10560-10564

58 Kong D, Le L T, Li Y, et al. Temperature-dependent electrical properties of graphene inkjet-printed on flexible materials. Langmuir, 2012, 28: 13467-13472

$59 \mathrm{Li} \mathrm{W}$, Li F, Li H, et al. Flexible circuits and soft actuators by printing assembly of graphene. ACS Appl Mater Interfaces, 2016, 8: $12369-12376$

60 Wlasny I, Rogala M, Dabrowski P, et al. Finding optimal HBr reduction of inkjet printed graphene oxide for flexible electronics. Mater Chem Phys, 2016, 181: 409-414

61 Le L T, Ervin M H, Qiu H, et al. Graphene supercapacitor electrodes fabricated by inkjet printing and thermal reduction of graphene oxide. Electrochem Commun, 2011, 13: 355-358

62 Huang L, Huang Y, Liang J J, et al. Graphene-based conducting inks for direct inkjet printing of flexible conductive patterns and their applications in electric circuits and chemical sensors. Nano Res, 2011, 4: 675-684

63 Shin K, Hong J, Jang J. Micropatterning of graphene sheets by inkjet printing and its wideband dipole-antenna application. Adv Mater, 2011, 23: 2113-2118

64 Mei Q, Zhang Z. Photoluminescent graphene oxide ink to print sensors onto microporous membranes for versatile visualization bioassays. Angew Chem Int Ed, 2012, 51: 5602-5606

65 Mattevi C, Eda G, Agnoli S, et al. Evolution of electrical, chemical, and structural properties of transparent and conducting chemically derived graphene thin films. Adv Funct Mater, 2009, 19: 2577-2583

66 Dua V, Surwade S P, Ammu S, et al. All-organic vapor sensor using inkjet-printed reduced graphene oxide. Angew Chem Int Ed, 2010, 49: 2154-2157

67 Arapov K, Abbel R, de With G, et al. Inkjet printing of graphene. Faraday Discuss, 2014, 173: 323-336

68 Lim S, Kang B, Kwak D, et al. Inkjet-printed reduced graphene oxide/poly(vinyl alcohol) composite electrodes for flexible transparent organic field-effect transistors. J Phys Chem C, 2012, 116: 7520-7525

$69 \mathrm{Lu} \mathrm{T}$, Zhang Y, Li H, et al. Electrochemical behaviors of graphene- $\mathrm{ZnO}$ and graphene-SnO ${ }_{2}$ composite films for supercapacitors. Electrochim Acta, 2010, 55: 4170-4173

70 Baker J, Deganello D, Gethin D T, et al. Flexographic printing of graphene nanoplatelet ink to replace platinum as counter electrode catalyst in flexible dye sensitised solar cell. Mater Res Innov, 2014, 18: 86-90

71 Sinar D, Knopf G K, Nikumb S, et al. Printed optically transparent graphene cellulose electrodes. Proc SPIE, 2016: 974515

72 Minh-Hai T, Jeong H K. Synthesis and characterization of silver nanoparticles doped reduced graphene oxide. Chem Phys Lett, 2015, 630: $80-85$

73 Zhang W, Bi E, Li M, et al. Synthesis of Ag/RGO composite as effective conductive ink filler for flexible inkjet printing electronics. Colloid Surface A, 2016, 490: 232-240

74 Jabari E, Toyserkani E. Aerosol-jet printing of highly flexible and conductive graphene/silver patterns. Mater Lett, 2016, 174: 40-43

75 Choo D C, Kim T W. Conducting transparent thin films based on silver nanowires and graphene-oxide flakes. J Electrochem Soc, 2015, 162: H419-H421

76 Zhang X M, Wang A M, Ke R, et al. Electrochemical synthesis and photoelectrochemical properties of a novel RGO/AgNDs composite. RSC Adv, 2015, 5: 32994-33000

77 Liu Z Y, Parvez K, Li R J, et al. Transparent conductive electrodes from graphene/PEDOT:PSS hybrid inks for ultrathin organic photodetectors. Adv Mater, 2015, 27: 669-675

78 Xu Y F, Hennig I, Freyberg D, et al. Inkjet-printed energy storage device using graphene/polyaniline inks. J Power Sources, 2014, 248: 483-488

79 Yuan Y, Peng B, Chi H, et al. Layer-by-layer inkjet printing SPS:PEDOT NP/RGO composite film for flexible humidity sensors. RSC Adv, 2016, 6: 113298-113306

80 Derby B. Inkjet printing of functional and structural materials: Fluid property requirements, feature stability, and resolution. Annu Rev Mater Res, 2010, 40: 395-414

81 Cummins G, Desmulliez M. Inkjet printing of conductive materials: A review. Circuit World, 2012, 38: 193-213

82 Finn D J, Lotya M, Coleman J N. Inkjet printing of silver nanowire networks. ACS Appl Mater Interfaces, 2015, 7: 9254-9261

83 Shin K, Hong J, Jang J. Flexible and transparent graphene films as acoustic actuator electrodes using inkjet printing. Chem Commun, 2011, 47: 8527-8529 
Stringer J, Derby B. Limits to feature size and resolution in ink jet printing. J Eur Ceram Soc, 2009, 29: 913-918

Lim J A, Cho J H, Jang Y, et al. Precise control of surface wettability of mixed monolayers using a simple wiping method. Thin Solid Films, 2006, 515: 2079-2084

Deegan R D, Bakajin O, Dupont T F, et al. Capillary flow as the cause of ring stains from dried liquid drops. Nature, 1997, 389: 827-829

Sun J, Kuang M, Song Y. Control and application of "coffee ring" effect in inkjet printing. Prog Chem, 2015, 27: 979-985

Derby B. Printing and prototyping of tissues and scaffolds. Science, 2012, 338: 921-926

Tobjork D, Osterbacka R. Paper electronics. Adv Mater, 2011, 23: 1935-1961

Tekin E, Smith P J, Schubert U S. Inkjet printing as a deposition and patterning tool for polymers and inorganic particles. Soft Matter, 2008, 4: 703-713

de Gans B J, Duineveld P C, Schubert U S. Inkjet printing of polymers: State of the art and future developments. Adv Mater, 2004, 16: 203-213

Calvert P. Inkjet printing for materials and devices. Chem Mater, 2001, 13: 3299-3305

Hyun W J, Secor E B, Hersam M C, et al. High-resolution patterning of graphene by screen printing with a silicon stencil for highly flexible printed electronics. Adv Mater, 2015, 27: 109-115

Park K S, Lee K S, Kang C, et al. Cross-stacked single-crystal organic nanowire p-n nanojunction arrays by nanotransfer printing. Nano Lett, 2015, 15: 289-293

Meitl M A, Zhou Y, Gaur A, et al. Solution casting and transfer printing single-walled carbon nanotube films. Nano Lett, 2004, 4: 1643-1647

Cerf A, Alava T, Barton R A, et al. Transfer-printing of single DNA molecule arrays on graphene for high-resolution electron imaging and analysis. Nano Lett, 2011, 11: 4232-4238

Guilhabert B, Hurtado A, Jevtics D, et al. Transfer printing of semiconductor nanowires with lasing emission for controllable nanophotonic device fabrication. ACS Nano, 2016, 10: 3951-3958

Li S, Peele B N, Larson C M, et al. A stretchable multicolor display and touch interface using photopatterning and transfer printing. Adv Mater, 2016, 28: 9770

Oh D W, Kim S, Rogers J A, et al. Interfacial thermal conductance of transfer-printed metal films. Adv Mater, 2011, 23: 5028-5033

Hines D R, Ballarotto V W, Williams E D, et al. Transfer printing methods for the fabrication of flexible organic electronics. J Appl Phys, 2007, 101: 24503

1 Li Z, Liu H, Ouyang C, et al. Recent advances in pen-based writing electronics and their emerging applications. Adv Funct Mater, 2016, 26: $165-180$

2 Takei K, Yu Z, Zheng M, et al. Highly sensitive electronic whiskers based on patterned carbon nanotube and silver nanoparticle composite films. Proc Natl Acad Sci USA, 2014, 111: 1703-1707

Harada S, Honda W, Arie T, et al. Fully printed, highly sensitive multifunctional artificial electronic whisker arrays integrated with strain and temperature sensors. ACS Nano, 2014, 8: 3921-3927

Mirica K A, Azzarelli J M, Weis J G, et al. Rapid prototyping of carbon-based chemiresistive gas sensors on paper. Proc Natl Acad Sci USA, 2013, 110: 3265-3270

Minemawari H, Yamada T, Matsui H, et al. Inkjet printing of single-crystal films. Nature, 2011, 475: 364-367

Liu L, Niu Z, Zhang L, et al. Nanostructured graphene composite papers for highly flexible and foldable supercapacitors. Adv Mater, 2014, 26: 4855-4862

Hyun W J, Park O O, Chin B D. Foldable graphene electronic circuits based on paper substrates. Adv Mater, 2013, 25: 4729-4734

Zhang Q, Huang L, Chang Q H, et al. Gravure-printed interdigital microsupercapacitors on a flexible polyimide substrate using crumpled graphene ink. Nanotechnology, 2016, 27: 105401

9 Fu K, Wang Y B, Yan C Y, et al. Graphene oxide-based electrode inks for 3D-printed lithium-ion batteries. Adv Mater, 2016, 28: 2587

Zhao C, Wang C, Gorkin R, et al. Three dimensional (3D) printed electrodes for interdigitated supercapacitors. Electrochem Commun, 2014, 41: 20-23

1 Sun K, Wei T, Ahn B Y, et al. 3D printing of interdigitated Li-ion microbattery architectures. Adv Mater, 2013, 25: 4539-4543

2 Hong S, Sycks D, Chan H F, et al. 3D printing of highly stretchable and tough hydrogels into complex, cellularized structures. Adv Mater, 2015, 27: 4035-4040

13 Jakus A E, Secor E B, Rutz A L, et al. Three-dimensional printing of high-content graphene scaffolds for electronic and biomedical applications. ACS Nano, 2015, 9: 4636-4648

4 Muth J T, Vogt D M, Truby R L, et al. Embedded 3D printing of strain sensors within highly stretchable elastomers. Adv Mater, 2014, 26: 6307-6312

115 Han Y, Wei C, Dong J. Super-resolution electrohydrodynamic (EHD) 3D printing of micro-structures using phase-change inks. Manuf 
Lett, 2014, 2: 96-99

116 Roman-Manso B, Figueiredo F M, Achiaga B, et al. Electrically functional 3D-architectured graphene/SiC composites. Carbon, 2016, 100: $318-328$

117 Zhu C, Han T Y, Duoss E B, et al. Highly compressible 3D periodic graphene aerogel microlattices. Nat Commun, 2015, 6: 6962

118 Zhang Q, Zhang F, Medarametla S P, et al. 3D printing of graphene aerogels. Small, 2016, 12: 1702-1708

119 Jakus A E, Shah R N. Multi and mixed 3D-printing of graphene-hydroxyapatite hybrid materials for complex tissue engineering. J Biomed Mater Res A, 2017, 105: 274-283

120 Gao Y, Shi W, Wang W, et al. Inkjet printing patterns of highly conductive pristine graphene on flexible substrates. Ind Eng Chem Res, 2014, 53: 16777-16784

121 Wan J, Gu F, Bao W, et al. Sodium-ion intercalated transparent conductors with printed reduced graphene oxide networks. Nano Lett, 2015, 15: 3763-3769

122 Georgakilas V, Demeslis A, Ntararas E, et al. Hydrophilic nanotube supported graphene-water dispersible carbon superstructure with excellent conductivity. Adv Funct Mater, 2015, 25: 1481-1487

123 Grande L, Chundi V T, Wei D, et al. Graphene for energy harvesting/storage devices and printed electronics. Particuology, 2012, 10: 1-8

124 Wei D, Grande L, Chundi V, et al. Graphene from electrochemical exfoliation and its direct applications in enhanced energy storage devices. Chem Commun, 2012, 48: 1239-1241

125 Ervin M H, Le L T, Lee W Y. Inkjet-printed flexible graphene-based supercapacitor. Electrochim Acta, 2014, 147: 610-616

126 Kelly A G, Finn D, Harvey A, et al. All-printed capacitors from graphene-BN-graphene nanosheet heterostructures. Appl Phys Lett, 2016, 109: 23107

127 Hempel M, Nezich D, Kong J, et al. A novel class of strain gauges based on layered percolative films of 2D materials. Nano Lett, 2012, 12: $5714-5718$

128 Chen Z, Ming T, Goulamaly M M, et al. Enhancing the sensitivity of percolative graphene films for flexible and transparent pressure sensor arrays. Adv Funct Mater, 2016, 26: 5061-5067

129 Kim J, Kumar R, Bandodkar A J, et al. Advanced materials for printed wearable electrochemical devices: A review. Adv Electron Mater, 2017, 3: 1600260

130 Bardpho C, Rattanarat P, Siangproh W, et al. Ultra-high performance liquid chromatographic determination of antioxidants in teas using inkjet-printed graphene-polyaniline electrode. Talanta, 2016, 148: 673-679

131 Wang D Z, Zha W, Feng L, et al. Electrohydrodynamic jet printing and a preliminary electrochemistry test of graphene micro-scale electrodes. J Micromech Microeng, 2016, 26: 045010

132 Finn D J, Lotya M, Cunningham G, et al. Inkjet deposition of liquid-exfoliated graphene and $\mathrm{MoS}_{2}$ nanosheets for printed device applications. J Mater Chem C, 2014, 2: 925-932

133 Wisitsoraat A, Mensing J P, Karuwan C, et al. Printed organo-functionalized graphene for biosensing applications. Biosens Bioelectron, 2017, 87: 7-17 


\title{
Recent developments in graphene conductive ink: Preparation, printing technology and application
}

\author{
JIANG Xin ${ }^{1,2}$, ZHAO XuanLiang ${ }^{1,2}$, LI Jing $^{1}$, LIN ShuYuan ${ }^{1,2} \&$ ZHU HongWei ${ }^{1,2^{*}}$ \\ ${ }^{1}$ State Key Laboratory of New Ceramics and Fine Processing, School of Materials Science and Engineering, Tsinghua University, Beijing 100084, China; \\ ${ }^{2}$ Center for Nano and Micro Mechanics, Tsinghua University, Beijing 100084, China \\ * Corresponding author, E-mail: hongweizhu@ tsinghua.edu.cn
}

Electronic printing is an interdisciplinary technology of traditional printing technology and microelectronics manufacturing. The development of electronic printing has mostly benefited from the progress of nanomaterials research. Graphene, a novel two-dimensional carbon nanomaterial, has shown excellent electrical, thermal, optical properties in flexible electrical devices. Graphene with traditional metals or polymer materials together could act as the main conductive components in conductive ink. Printing of graphene ink represents a cost-effective deposition technique to obtain patterned conductive graphene films, and further assemble them into functional electrical devices. Therefore, electronic printing based on graphene conductive ink is one of the recent research hotspots.

In this paper, we review recent developments and advances in research of graphene conductive ink. This review begins with an introduction of different preparation strategies for graphene conductive inks. For printing, the three major pathways for producing graphene sheets are oxidation-reduction, solvent exfoliation and electrochemical expansion of graphite. Different preparation strategies for conductive inks are classified into three major methods: Graphene inks stabilized by surfactants or functional groups, and graphene-based composite conductive ink. The detailed review of graphene conductive ink preparation is discussed with specific examples. Preparation of graphene conductive inks of high concentrations, stability and printing adaptability is the key issue in electronic printing.

Subsequently, an introduction of common printing methods and principles is given. Five printing methods are discussed in this review, including inkjet printing, gravure printing, transfer printing, direct writing and threedimensional (3D) printing. Printing is kind of additive manufacturing, by depositing graphene onto substrates of various materials, sizes, flexibility and roughness for conductive pattern. Different printing techniques have unique requirements of ink rheological properties. The inkjet printing is becoming the most common technique employed in both academic research and industrial application. The realization of rapid, accurate, simple and controllable printing has important influence on the application of graphene conductive ink.

Finally, applications of printed graphene conductive ink in flexible functional devices, including basic electrical circuits, energy storage devices and mechanical/chemical sensing devices, are envisioned. Basic electrical circuits, like flexible conductive patterns, field-effect transistors and radio-frequency circuits, play an important role in the fabrication of wearable devices. Printing also offers a cheap, scalable method of fabricating energy storage devices, including supercapacitor and lithium battery. The unique structure of graphene makes possible the fabrication of different kinds of sensors, including strain, temperature, chemical, electrochemical, photo-electricity sensors and biosensors. An outlook of potential future trends in printing graphene conductive ink research and technology is followed.

In summary, printing graphene conductive ink has made many significant advances in a wide range of applications. However, the industrial-level application is still limited, and the preparation and application of graphene conductive ink still need further study. A number of key issues should be solved, including stability of graphene ink, electronic conductivity of printed circuit, limited printing resolution, etc. Overall, electronic printing technology based on graphene conductive ink is not meant as a replacement for microelectronic manufacturing engineering, but instead provides an opportunity to produce large-area flexible electronic devices at low cost. Electronic printing of graphene conductive ink will result in a diverse range of novel applications in many fields, and it calls for more research in the future.

printed electronics, graphene, carbon nanomaterials, conductive ink, flexible electronics 